\title{
Copper-catalyzed enantioselective conjugate addition of organometallic reagents to challenging Michael acceptors
}

\author{
Delphine Pichon, Jennifer Morvan, Christophe Crévisy and Marc Mauduit ${ }^{*}$
}

\author{
Review \\ Address: \\ Université de Rennes, Ecole Nationale Supérieure de Chimie de \\ Rennes, CNRS, ISCR - UMR 6226, F-35000 Rennes, France \\ Email: \\ Marc Mauduit ${ }^{\star}$ - marc.mauduit@ensc-rennes.fr \\ * Corresponding author \\ Keywords: \\ acylimidazole; $N$-acyloxazolidinone; $N$-acylpyrrole; \\ $\mathrm{N}$-acylpyrrolidinone; aldehyde; amide; copper catalysis; \\ electron-deficient alkenes; enantioselective conjugate addition; \\ Michael acceptor; thioester
}

\author{
Beilstein J. Org. Chem. 2020, 16, 212-232. \\ doi:10.3762/bjoc. 16.24
}

Received: 22 November 2019

Accepted: 04 February 2020

Published: 17 February 2020

This article is part of the thematic issue "Copper-catalyzed reactions for organic synthesis".

Guest Editor: G. Evano

(C) 2020 Pichon et al.; licensee Beilstein-Institut. License and terms: see end of document.

\begin{abstract}
The copper-catalyzed enantioselective conjugate addition (ECA) of organometallic nucleophiles to electron-deficient alkenes (Michael acceptors) represents an efficient and attractive methodology for providing a wide range of relevant chiral molecules. In order to increase the attractiveness of this useful catalytic transformation, some Michael acceptors bearing challenging electrondeficient functions (i.e., aldehydes, thioesters, acylimidazoles, $N$-acyloxazolidinones, $N$-acylpyrrolidinones, amides, $\mathrm{N}$-acylpyrroles) were recently investigated. Remarkably, only a few chiral copper-based catalytic systems have successfully achieved the conjugate addition of different organometallic reagents to these challenging Michael acceptors, with excellent regioand enantioselectivity. Furthermore, thanks to their easy derivatization, the resulting chiral conjugated products could be converted into various natural products. The aim of this tutorial review is to summarize recent advances accomplished in this stimulating field.
\end{abstract}

\section{Introduction}

Generating high molecular complexity and controlling multiple stereogenic centers in a minimum number of steps is nowadays one of the most important challenges in organic chemistry for the synthesis of complex chiral molecules. The transition metal (TM)-catalyzed enantioselective conjugate addition (ECA) of nucleophiles to electron-deficient alkenes (Michael acceptors) is one of the most relevant and versatile methods to achieve this goal [1-4]. Among the plethora of metals studied, copper-based catalytic systems proved to be highly efficient for the conjugate addition of various organometallic reagents, such as diorganozinc, triorganoaluminium, and Grignard reagents to Michael acceptors. In that respect, since the pioneering example reported by Alexakis and co-workers in 1993 [5], a wide range of cyclic and acyclic electron-deficient alkenes, such as $\alpha, \beta$-unsaturated ketones, esters, nitriles, sulfones, or nitroolefines, was intensively studied, leading to the expected 1,4-products in excellent yields and remarkable enantioselectivities. More recently, tremendous breakthroughs were achieved in this 
field, notably by the formation of all-carbon quaternary chiral centers [6] and the challenging 1,6-, 1,8-, or 1,10-selective addition to cyclic or aliphatic polyenic substrates [7-9]. Furthermore, $\mathrm{Cu}$ ECA transformations were also successfully applied to the synthesis of natural products [10]. Nevertheless, it is worth to underline that the choice of the electron-withdrawing group (EWG) on the Michael substrates appears not so simple. First, the hardness of the involved organometallic reagents has to be considered in order to overcome or limit undesirable side reactions. Although the main role of copper is to form a transient organocuprate reactive species with the hard nucleophiles to avoid the formation of the nondesired 1,2-product, some Grignard or aluminium reagents remain too reactive and incompatible with some electron-withdrawing functions. In contrast, some organometallic reagents, such as dimethylzinc, are poorly reactive and require a higher electrophilicity of the Michael acceptors to provide the desired conjugated products. Second, in order to be attractive for the total synthesis of relevant molecules, the involved EWG should preferably allow readily applicable and practicable postfunctionalizations [10].

Among the plethora of studied Michael acceptors, $\alpha, \beta$-unsaturated aldehydes, thioesters, acylimidazoles, $N$-acyloxazolidinones, $\mathrm{N}$-acylpyrrolidinones, amides, and $\mathrm{N}$-acylpyrroles have been scarcely investigated in $\mathrm{Cu}$ ECA despite their usefulness for postfunctionalizations. This tutorial review aims to describe the early examples and recent advances in copper-catalyzed asymmetric conjugate additions of dialkylzinc, Grignard, or trialkylaluminium reagents toward those challenging substrates and their fruitful application in the total synthesis of natural products.

\section{Review \\ Enantioselective conjugate addition to challenging Michael acceptors Copper-catalyzed ECA to $\alpha, \beta$-unsaturated aldehydes}

Nowadays, $\beta$-substituted enals represent probably the most challenging Michael acceptors in the copper-catalyzed ECA of organometallic reagents [11-13]. This challenge is reinforced by the fact that the resulting chiral $\beta$-functionalized aldehydes are considered as an important motif that is ubiquitous in numerous natural molecules. However, as depicted in Scheme 1, due to their stronger reactivity than that of usual esters or ketones, a competitive 1,2-addition to the carbonyl function of enals could occur, leading to the corresponding alcohol as a byproduct. Moreover, even if the 1,4-addition is favored, thanks to the copper/ligand catalytic species, the resulting metallic enolate intermediate can also react with the starting material to form the aldol byproduct, significantly altering the yield of the expected 1,4-product (Scheme 1).

The first successful copper-catalyzed ECA to $\alpha, \beta$-unsaturated aldehydes with organozinc and Grignard reagents was reported by Alexakis and co-workers in 2010 [14]. After screening various chiral phosphine-based ligands, the combinations of either phosphoramidite $\mathbf{L 1}$ with $\mathrm{Cu}(\mathrm{OTf})_{2}$, or $(R)$-BINAP (L2) with copper thiophenecarboxylate (CuTC) appeared to be the most efficient for the addition of $\mathrm{Et}_{2} \mathrm{Zn}$ to a variety of cyclic and acyclic aldehydes 1. High 1,4-regioselectivities and promising stereoselectivities ranging from 27 to $90 \%$ ee were achieved (Scheme 2a). It is noteworthy that the addition of dimethylzinc was also successfully achieved, as the desired 1,4-methylated

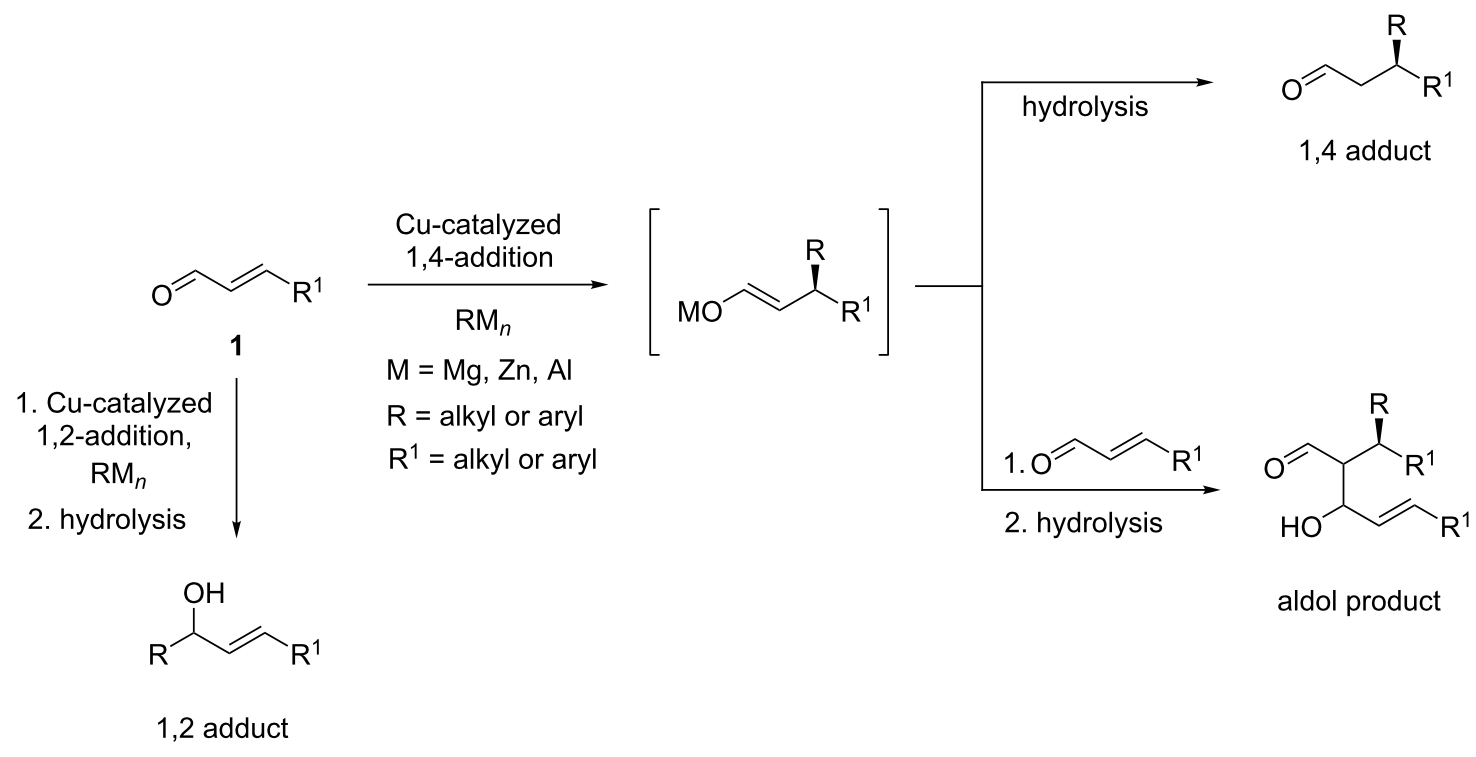




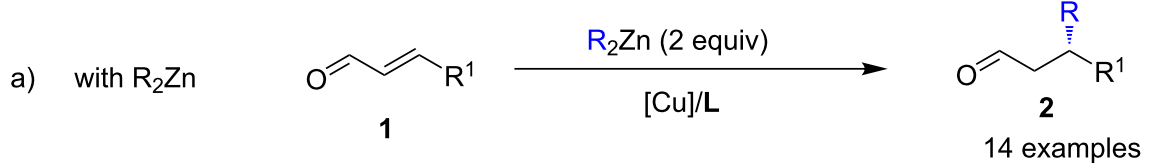

$\mathrm{R}^{1}=\mathrm{alkyl}$, aryl

1,4 ratio between 53 and $100 \%$

$27-90 \%$ ee

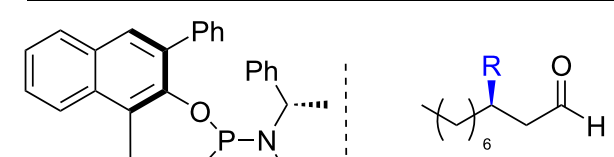

2a: $\mathrm{R}=\mathrm{Me}$ $1,4: 1,2$ :aldol $100: 0: 0$ $100 \%$ conv, $60 \%$ ee

2b: $\mathrm{R}=\mathrm{Et}$

1,4:1,2:aldol 95:0:5

$88 \%$ conv, $79 \%$ ee

$\mathrm{Cu}(\mathrm{OTf})_{2}(5 \mathrm{~mol} \%)$

L1 (10 mol \%),

toluene,

$0{ }^{\circ} \mathrm{C}, 4.5 \mathrm{~h}$

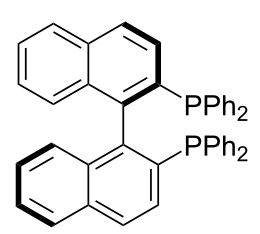

(R)-BINAP

L2

CuTC (5 mol \%),

L2 (5.25 mol \%),

$\mathrm{Et}_{2} \mathrm{O},-20^{\circ} \mathrm{C}(6 \mathrm{~h})$

or $0^{\circ} \mathrm{C}(16 \mathrm{~h})$

b) with $\mathrm{RMgBr}$ 2a: $\mathrm{R}=\mathrm{Me}$ 1,4:1,2:aldol 100:0:0 $85 \%$ conv, $68 \%$ ee

\section{2b: $\mathrm{R}=\mathrm{Et}$} 1,4:1,2:aldol 100:0:0 $100 \%$ conv, $75 \%$ ee

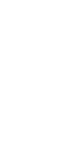<smiles>[R]C(CC=O)C1CCCCC1</smiles>

2c: $\mathrm{R}=\mathrm{Et}$

1,4:1,2:aldol $100: 0: 0$ $100 \%$ conv, $90 \%$ ee<smiles>[R]C(CC=O)c1ccccc1</smiles>

2e: $\mathrm{R}=\mathrm{Et}$

1,4:1,2:aldol 92:0:8 $81 \%$ conv, $82 \%$ ee<smiles>CCC1CCCCC1C=O</smiles>

$2 \mathrm{~g}$

1,4:1,2:aldol 53:47:0 $100 \%$ conv, $60 \%$ ee 2d: $\mathrm{R}=\mathrm{Me}$

1,4:1,2:aldol 100:0:0 $87 \%$ conv, $60 \%$ ee

2c: $\mathrm{R}=\mathrm{Et}$

1,4:1,2:aldol 100:0:0 $100 \%$ conv, $52 \%$ ee<smiles>[R]C(CC=O)C(C)(C)C</smiles>

2f: $\mathrm{R}=\mathrm{Me}$

1,4:1,2:aldol 100:0:0, 1,4:1,2:aldol 100:0:0 $50 \%$ conv, $64 \%$ ee $\quad 87 \%$ conv, $76 \%$ ee

2e: $\mathrm{R}=\mathrm{Et}$

1,4:1,2:aldol 100:0:0

$100 \%$ conv, $44 \%$ ee 2i: $\mathrm{R}=\mathrm{Et}$

1,4:1,2:aldol 100:0:0 $100 \%$ conv, $64 \%$ ee

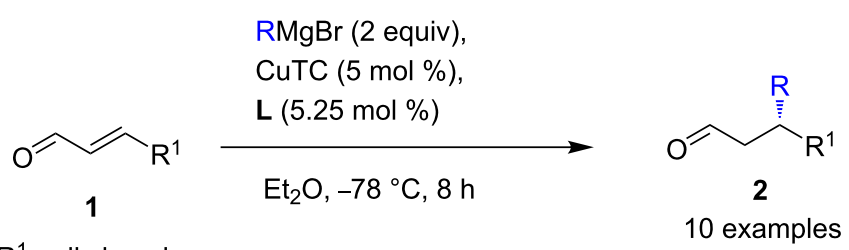

$\mathrm{R}^{1}=$ alkyl, aryl<smiles>c1ccc(-c2ccc3ccccc3c2-c2c(P(c3ccccc3)c3ccccc3)ccc3ccccc23)cc1</smiles>

$(R)$-BINAP L2

L3 + TMSCl (1.3 equiv) 2b: $\mathrm{R}=\mathrm{Et}$ 1,4:1,2:aldol $62: 38: 0$ $98 \%$ conv, $89 \%$ ee 1,4:1,2:aldol 85:15:0 $100 \%$ conv, $90 \%$ ee

2a: $\mathrm{R}=\mathrm{Me}$ 1,4:1,2:aldol 65:35:0 $100 \%$ conv, $81 \%$ ee

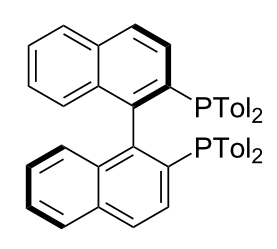

$(R)$-ToIBINAP

L3 2b: $\mathbf{R}=\mathrm{Et}$

1,4:1,2:aldol 32:42:26 $99 \%$ conv, $92 \%$ ee

Scheme 2: Cu-catalyzed ECA of $\alpha, \beta$-unsaturated aldehydes with phosphoramidite- (a) and phosphine-based ligands (b). 
products were exclusively formed in moderate to good yields, with ee values of up to $76 \%$. When the conjugate addition was performed with Grignard reagents, significant amounts of 1,2products and enols were formed, despite the use of cryogenic conditions. ( $R$ )-BINAP (L2) gave the best regio- and enantioselectivity, with $62 \%$ of the 1,4-product and $89 \%$ ee with EtMgBr (Scheme 2b). To overcome the low regioselectivity, the authors took into account previous works showing that the 1,4-regioselectivity in the addition of cuprates to enals could be improved in the presence of a slight excess of TMSCl [15-19]. Indeed, using $\mathrm{TMSCl}$ in combination with $(R)$-TolBINAP $(\mathbf{L 3})$, a promising $85 \%$ regioselectivity was observed, without altering the enantioselectivity ( $90 \%$ ee), whereas only $32 \%$ of the desired 1,4- product was obtained without TMSCl [20]. With those op- timized conditions, various enals and Grignard reagents were screened. Nevertheless, despite the presence of $\mathrm{TMSCl}$, the $1,4: 1,2$ ratio varied significantly (from $85: 15$ to $10: 90$ ), while the level of enantioselectivity remained relatively good, reaching up to $90 \%$.

Following this, Alexakis and Quintard invented an efficient stepwise one-pot copper-catalyzed asymmetric ECA/organocatalyzed $\alpha$-substitution of enals [21]. By using (R)-BINAP (L2)/ CuTC in combination with chiral prolinol derivatives L4-6 as organocatalysts, various $\alpha, \beta$-functionalized aldehydes were synthesized in good isolated yields (57-74\%) and remarkable enantioselectivity (99\%) from diethylzinc or dimethylzinc as nucleophiles and vinyl sulfones as electrophiles (Scheme 3). Of note,

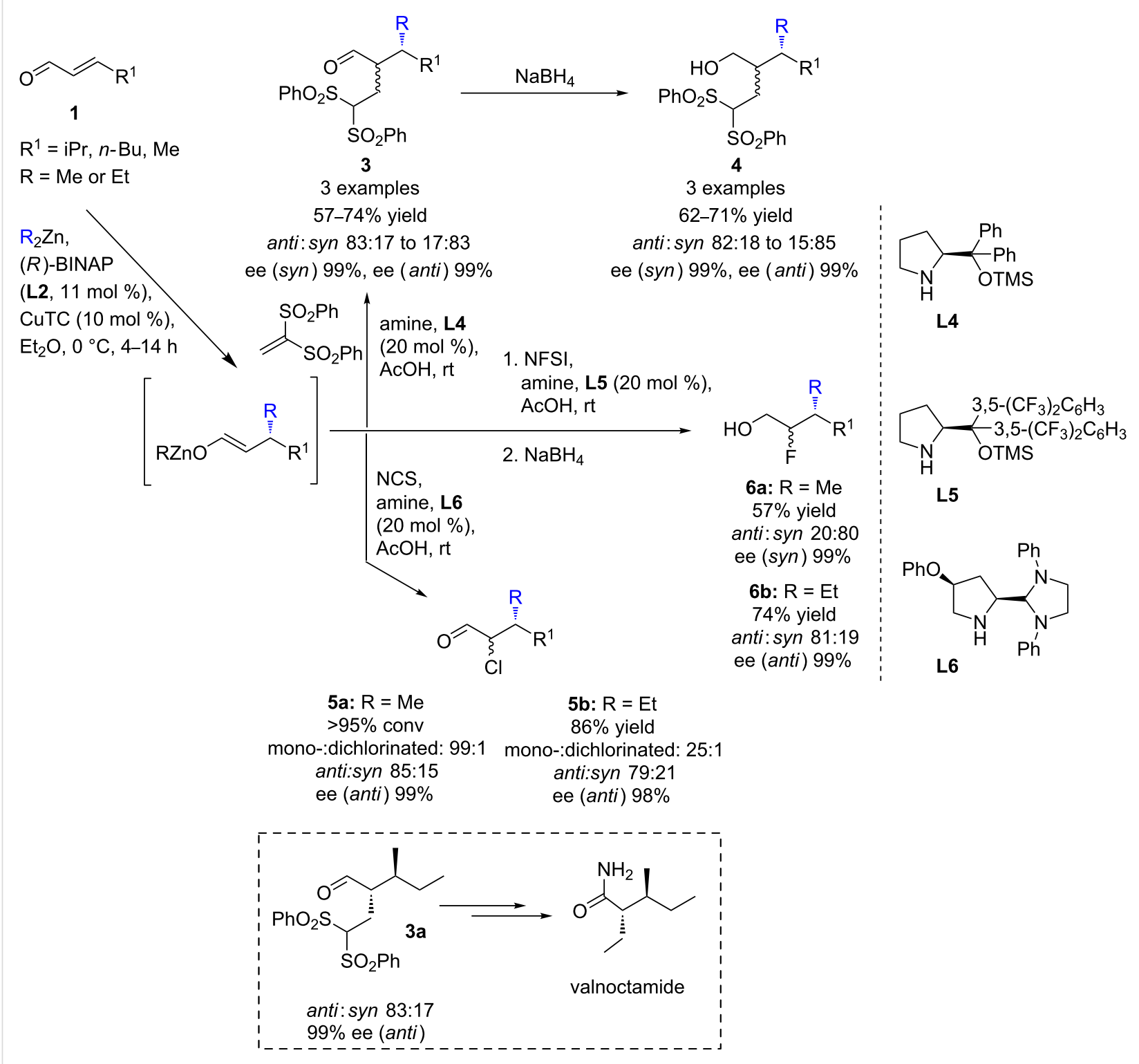

Scheme 3: One-pot Cu-catalyzed ECA/organocatalyzed $\alpha$-substitution of enals. 
both the anti- and the syn-product could be predominantly formed (with a anti:syn ratio from $83: 17$ to $15: 85$ ), and no diastereocontrol occurred in the absence of the organocatalyst. Interestingly, this simple protocol was successfully applied to the enantioselective synthesis of valnoctamide, a commercialized mild tranquilizer. Finally, this methodology was extended to the sequential Michael/halogenation reaction using NFSI or NCS as electrophiles, with similar efficiency.

Similarly, a cocatalyzed enantioselective $\beta$-functionalization of enals was developed by Córdova, Ibrahem, and co-workers in 2011 (Scheme 4) [22]. By mixing high catalytic loadings of $\mathrm{Cu}(\mathrm{OTf})_{2}, \mathrm{PPh}_{3}$, and TMS-protected diarylprolinol $\mathbf{L 4}$, the conjugate addition of $\mathrm{Et}_{2} \mathrm{Zn}$ or $\mathrm{Me}_{2} \mathrm{Zn}$ to various $\beta$-substituted enals proved to be highly enantioselective (ee up to $96 \%$ ), but moderate to good 1,4:1,2 ratios were obtained (51:49 to 97:3). Of note, chiral phosphines were also screened, but without any improvement of selectivity. Furthermore, this methodology was then efficiently applied to the total synthesis of several bisabolane sesquiterpenes, which exhibited anticancer and antimicrobial activities or are employed as ingredients in perfumes and cosmetics (Scheme 4).
The last report on ECAs of enals [23] was disclosed in 2016 by Alexakis and co-workers [24]. They achieved to develop three sets of optimized conditions for the CuTC-catalyzed conjugate addition of diorganozinc compounds, Grignard, and triorganoaluminium reagents to $\alpha, \beta$-unsaturated aldehydes (Scheme 5). With diethyl- and dimethylzinc, and in the presence of the most efficient chiral ligand $(R)-\mathrm{H}_{8}$-BINAP (L7), moderate to excellent regioselectivities $(1,4: 1,2$ ratios up to $100: 0)$ were observed, and the desired 1,4-products were formed with remarkable enantioselectivities ( 58 to $96 \%$ ee). With Grignard reagents, the best ee values ( 45 to $90 \%$ ) were obtained with $(R)$ TolBINAP (L3), but despite the presence of TMSCl, the regioselectivities remained modest, with a highest 1,4:1,2 ratio of 85:15. At last, $(R)$-SEGPHOS (L8) promoted the conjugate addition of $\mathrm{Me}_{3} \mathrm{Al}$ to cinnamaldehyde, with a remarkable $96 \%$ ee and a moderate 1,4:1,2 ratio. However, albeit no trace of aldol byproduct was detected, the reaction was incomplete $(66 \%$ conversion). The use of TMSCl improved the conversion to $88 \%$, but this was detrimental to the enantiocontrol ( $8 \%$ ee). These methodologies were applied to the straightforward synthesis of valuable $(R)$-citronellal and $(S)$-Florhydral ${ }^{\circledR}$, which were obtained with excellent enantioselectivities (87 and $96 \%$,

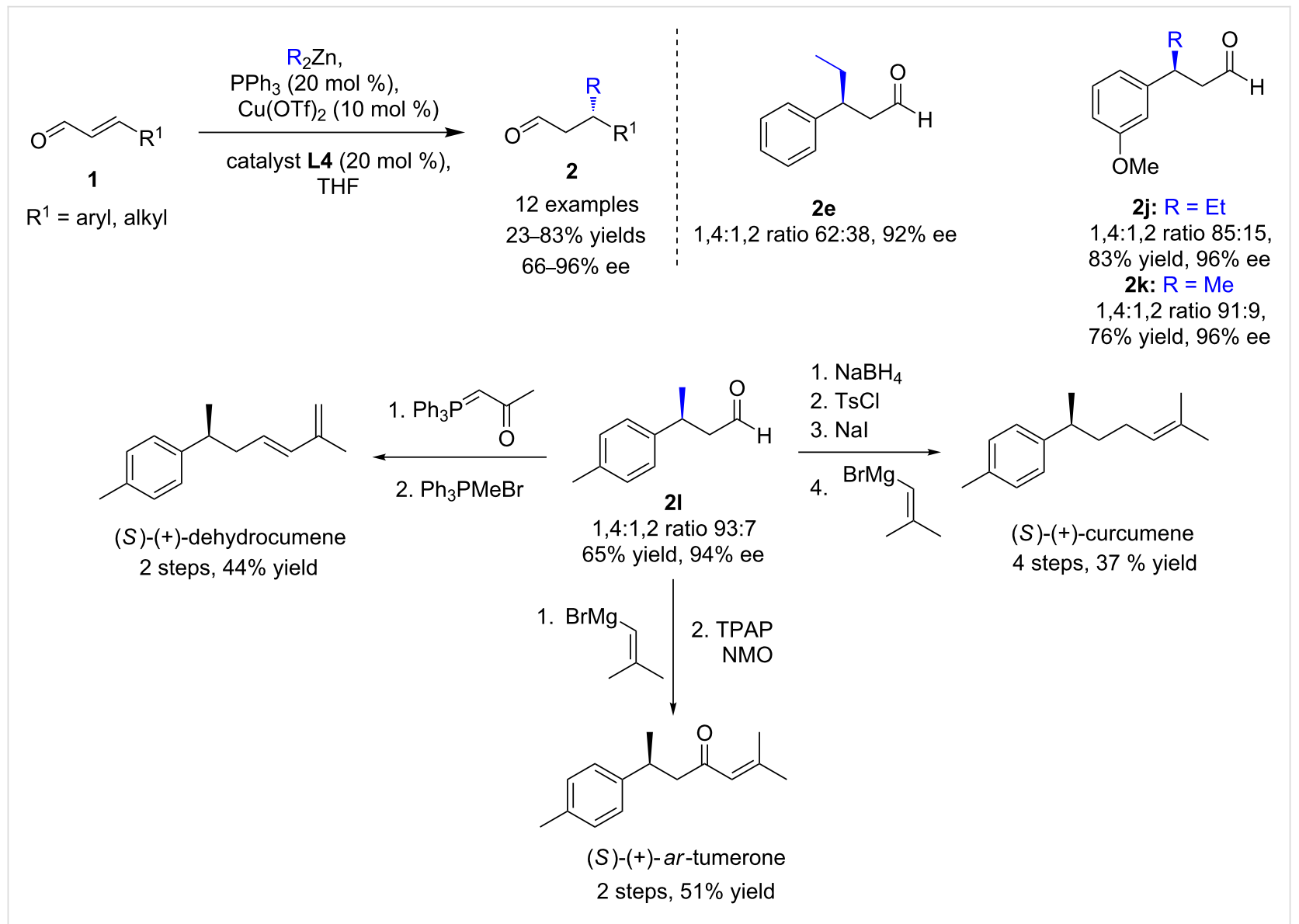

Scheme 4: Combination of copper and amino catalysis for enantioselective $\beta$-functionalizations of enals. 


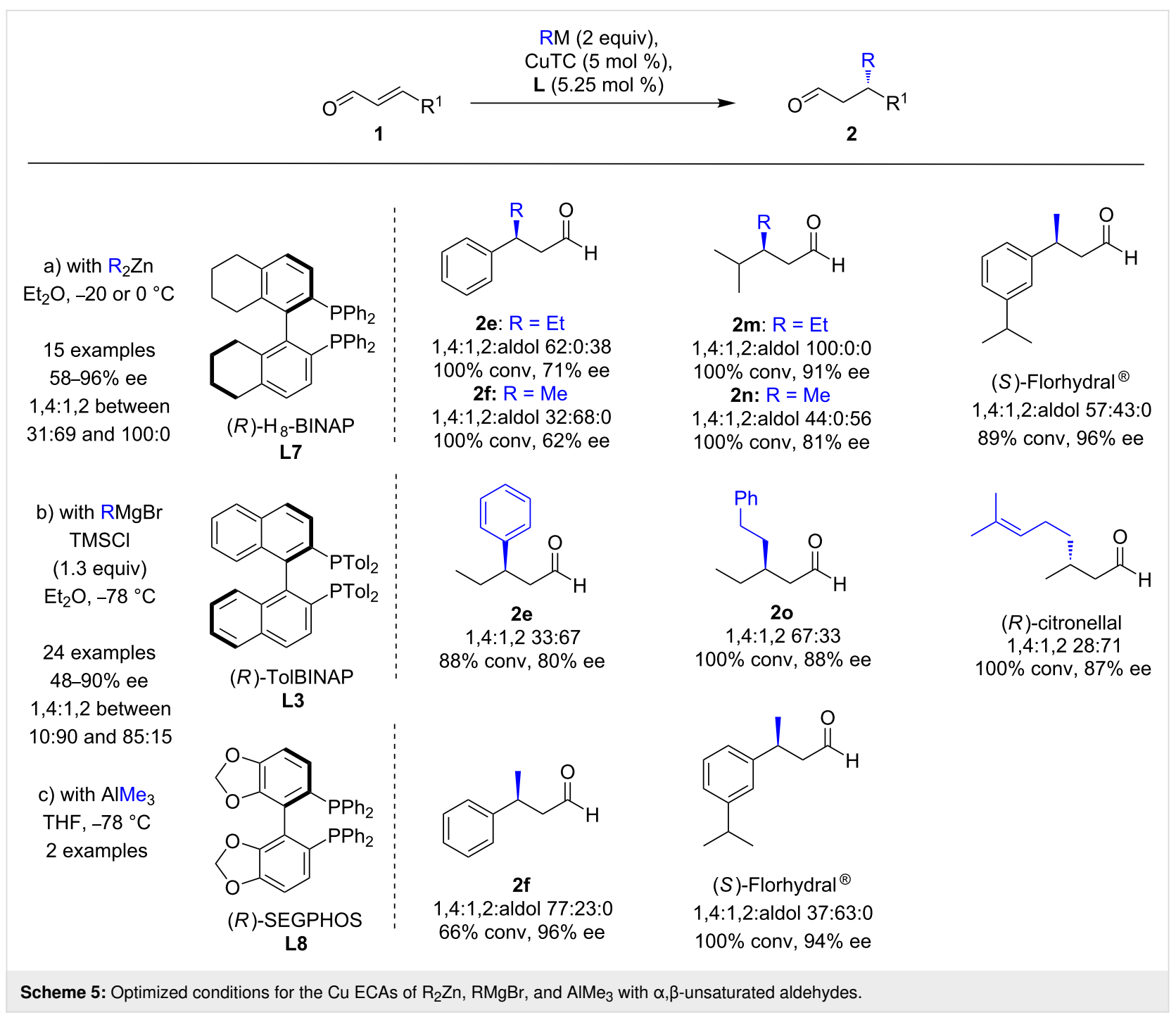

respectively). However, moderate to significant amounts of the 1,2-products were also formed.

As highlighted by these pioneering works, the direct copper-catalyzed conjugate addition of organometallic reagents to $\alpha, \beta$ unsaturated aldehydes still remains an important challenge. Albeit some promising excellent regioselectivities and high enantioselectivities were achieved, this was often limited to a few organometallic reagents/enal substrates, as mentioned above. In that respect, indirect pathways were developed as alternative strategies, involving electron-deficient functions that can subsequently easily be converted to aldehydes.

\section{$\alpha, \beta$-Unsaturated thioesters}

In 2005, Feringa, Minnaard, and co-workers were the first to report the ECA of Grignard reagents to $\alpha, \beta$-unsaturated thioesters [25]. Advantageously, the latter were also readily accessible but significantly more reactive than $\alpha, \beta$-unsaturated esters. Indeed, the thioester fragments featured a reduced electron delocalization compared to oxoesters, which resulted in a higher reactivity in conjugate additions, even with the less reactive $\mathrm{MeMgBr}$. As depicted in Scheme 6, excellent yields and remarkable enantioselectivities (up to $96 \%$ ) were obtained in ECAs of linear aliphatic Grignard reagents (in particular $\mathrm{MeMgBr}$ ) to a wide range of substrates, catalyzed by $\mathrm{CuBr} \cdot \mathrm{SMe}_{2} /(R, S)-J o s i p h o s(\mathbf{L 9})$.

However, the catalytic system was poorly selective toward sterically hindered organomagnesium nucleophiles (15-25\% ee). The synthetic versatility of the thioester function was illustrated in the synthesis of (-)-lardolure (26\% overall yield over 12 steps) via a relevant diastereoselective and enantioselective iterative route, affording the highly desirable deoxypropionate moiety in high $97 \%$ de. The Josiphos (L9)/CuBr$\cdot \mathrm{SMe}_{2}$ catalytic system was also efficient to promote the ECAs of $\mathrm{MeMgBr}$ to the less reactive aromatic $\alpha, \beta$-unsaturated thioesters (ee 


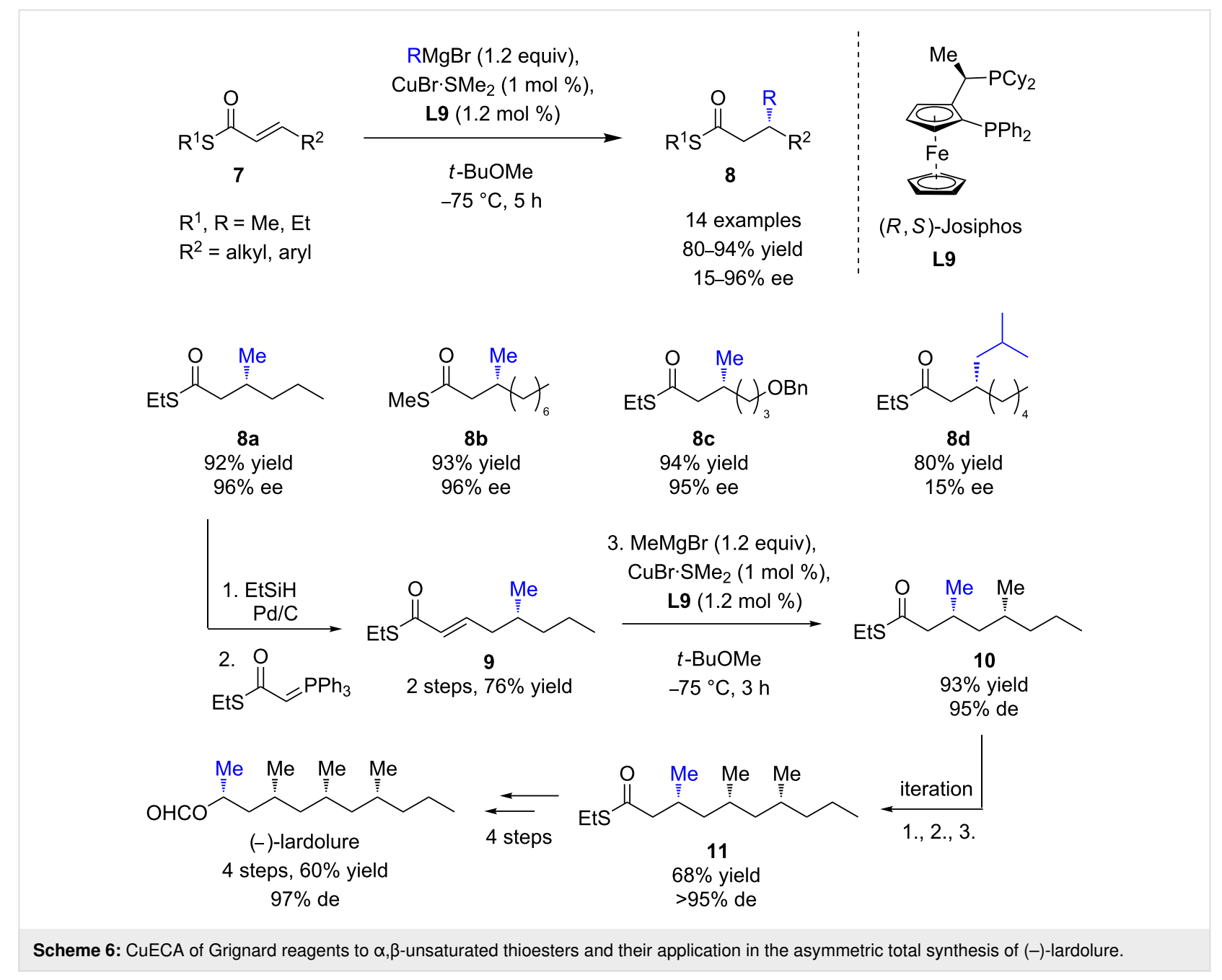

values up to $>99 \%$ ) [26]. In order to extend their methodology to less reactive bulky Grignard reagents and/or substrates, a catalytic system of wider application, involving $(S)$-TolBINAP (ent-L3)/CuI was developed by the same authors [26]. The expected 1,4-products were isolated in good yields and moderate to excellent enantioselectivities (up to $99 \%$ ee, Scheme 7), depending on the steric hindrance of the reagent. Unfortunately, the addition of $\mathrm{PhMgBr}$ remained unsuccessful. This powerful catalytic protocol was illustrated by Bates and Sridhar in the enantioselective total synthesis of (-)-mintlactone [27]. The key step, furnishing the $\beta$-methylated thioester $\mathbf{8 j}$, was accomplished in a good yield of $84 \%$ and a high ee of $94 \%$ (Scheme 7).

In 2008, Feringa and Minnaard evaluated the ECA of Grignard reagents to $\gamma$-substituted $\alpha, \beta$-unsaturated thioesters that could lead to vicinal (i.e., 1,2-relation) dialkyl arrays, a highly desirable moiety that is ubiquitous in a wide range of natural products [28]. As depicted in Scheme 8, TolBINAP (L3)/CuI, which appeared to be a better catalytic system than Josiphos (L9)/
$\mathrm{CuBr} \cdot \mathrm{SMe}_{2}$, afforded either the syn or anti 1,4 product $\mathbf{1 3}$ in good isolated yields and excellent diastereoselectivities and enantioselectivities (dr up to 99:1 and ee up to $>99.5$ ). The value of the protocol was successfully illustrated through the enantioselective total syntheses of (-)-lasiol and (+)-faranal, two useful natural pheromones.

Shortly after, Feringa, Minnaard, and co-workers demonstrated the efficiency of $(S, R)$-reversed Josiphos $(\mathbf{L 1 0})$ in the coppercatalyzed 1,6-ECA of $\mathrm{MeMgBr}$ to $\alpha, \beta, \gamma, \delta$-bisunsaturated thioesters $[29,30]$. The expected 1,6-products were selectively formed (the 1,6:1,4 ratio ranged from $85: 15$ to 99:1) in high yields (78-88\%) and good enantioselectivities (82-89\%, Scheme 9). It is worth to note that this protocol failed in the case of linear dienoates [29]. Interestingly, after a subsequent reconjugation step in the presence of DBU, the resulting enantioenriched $\gamma$-methylated $\alpha, \beta$-unsaturated thioester $\mathbf{1 8 a}$ was subsequently reacted in a $1,4-\mathrm{ECA}$ reaction catalyzed by Josiphos (L9)/CuBr$\cdot \mathrm{SMe}_{2}$. Using both enantiomers of the chiral ligand, either anti- or syn-1,3-deoxypropionate units were pro- 


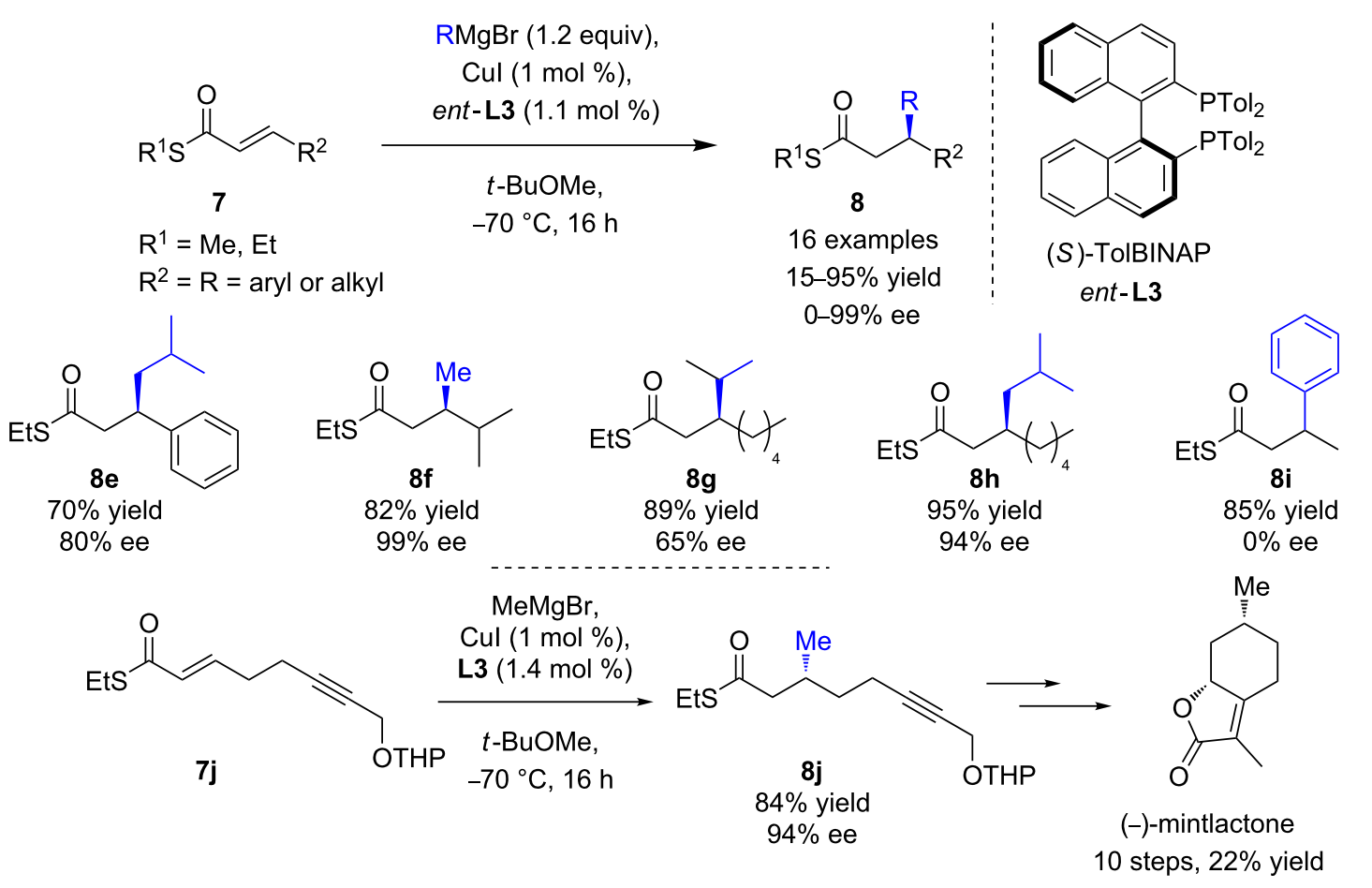

Scheme 7: Improved Cu ECA of Grignard reagents to $\alpha, \beta$-unsaturated thioesters, and their application in the asymmetric total synthesis of (-)-mintlactone.<smiles>[R1]C(/C=C/C(=O)[Se])c1ccccc1</smiles>

$\mathrm{R}^{1}$ and $\mathrm{R}^{2}=\mathrm{Me}$ or $\mathrm{Et}$<smiles>CCC(=O)CC(C)C(C)COCc1ccccc1</smiles>

$91 \%$ yield, $>99.5 \%$ ee dr (anti: syn): 98:2

\section{$\mathrm{R}^{2} \mathrm{MgBr}$ (3 equiv),}

Cul (3 mol \%)

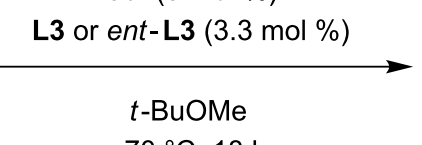

$-70{ }^{\circ} \mathrm{C}, 18 \mathrm{~h}$

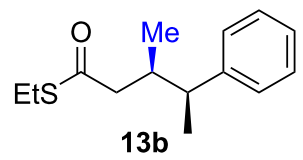

$82 \%$ yield, $>99.5 \%$ ee dr (anti: syn): 5:95<smiles>[R]C(CC(=O)SCC)C([R])c1ccccc1</smiles>

58-96\% yield

94-99.5\% ee

dr (anti : syn) 5:95 to $99: 1$<smiles>CCSC(=O)CC(CC)C(C)c1ccccc1</smiles>

$91 \%$ yield, $94 \%$ ee dr (anti: syn) 98:2

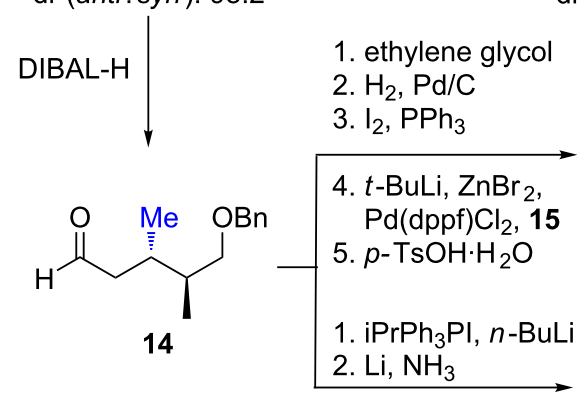<smiles>CC/C(C)=C\CC/C(C)=C/C[C@H](C)[C@H](C)CC=O</smiles>

(+)-faranal 5 steps, $38 \%$ yield<smiles>CC(C)=CC[C@H](C)[C@H](C)CO</smiles>

(-)-lasiol

3 steps, $86 \%$ yield 


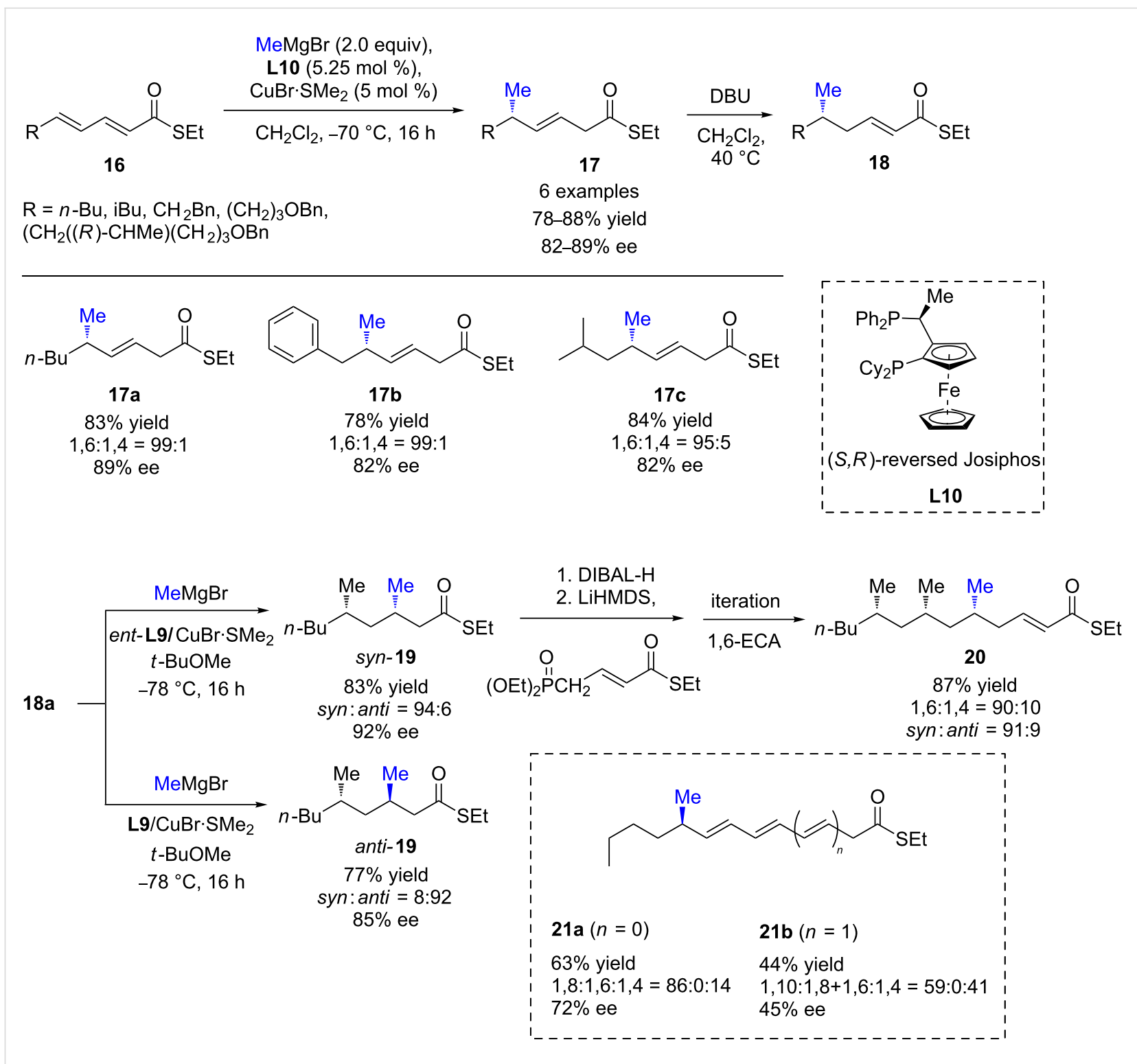

Scheme 9: 1,6-Cu ECA of MeMgBr to $\alpha, \beta, \gamma, \delta$-bisunsaturated thioesters: an iterative approach to deoxypropionate units.

duced in good yields and excellent enantioselectivities (85-92\% ee). Furthermore, an iterative procedure was also performed leading to all-syn or anti/syn-5,7,9-stereotriads, with high yields and stereoselectivity. This methodology was also tested on linear polyenic thioesters [9]. The challenging 1,8- and 1,10products $\mathbf{2 1 a} / \mathbf{b}$ were obtained, but the stereoselectivity dropped when the distance between the reacting olefin and the ester function was increased (1,8-ECA $72 \%$ ee; 1,10 -ECA $45 \%$ ee). However, the regioselectivity (59-86\%) and yield (44-63\%) remained decent.

The efficiency of TolBINAP ( $\mathbf{L 3}) / \mathrm{CuI}$ was also demonstrated in the ECA of Grignard reagents to the 4-chloro- $\alpha, \beta$-unsaturated thioester 22 [31]. Interestingly, the presence of the internal chloro leaving group allowed a powerful tandem conjugate addition-enolate trapping that led to valuable trans-1-alkyl-2substituted cyclopropanes (Scheme 10). Various Grignard reagents were used, affording the corresponding cyclopropanes in moderate to high yields (50-92\%) and good to excellent ee values (70-96\%), except for $\mathrm{PhMgBr}$ (26\% ee).

In 2010, Hall and Lee described a successful synthesis of enantioenriched boronate derivatives through catalytic ECA of Grignard reagents to 3-boronyl $\alpha, \beta$-unsaturated thioesters (Scheme 11) [32]. By applying an $\mathbf{L 3} / \mathrm{CuI}$ catalytic protocol previously developed by Feringa and Minnaard, $\mathrm{MeMgBr}$ and a range of aromatic Grignard reagents were selectively introduced, leading to the expected 1,4-products in high yields 


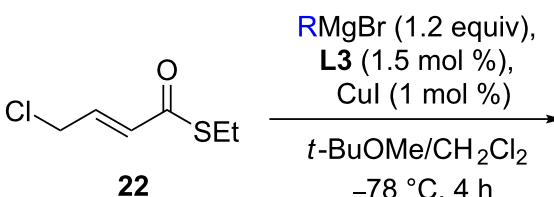

22

$-78{ }^{\circ} \mathrm{C}, 4 \mathrm{~h}$<smiles>[R]C(C=C([O-])O[Na])CCl</smiles>

23

\section{$-78^{\circ} \mathrm{C}$ to $\mathrm{rt}$,}

$4 \mathrm{~h}$

$\mathrm{R}=\mathrm{Me}, \mathrm{Et}$, iPr, iBu, hexyl, $\left(\mathrm{CH}_{2}\right)_{3} \mathrm{O} t-\mathrm{Bu}$, but-3-enyl, $\mathrm{BnCH}_{2}, \mathrm{Ph}$<smiles>[R]C1CC1C(=O)OCC</smiles>

10 examples $50-92 \%$ yield $26-96 \%$ ee<smiles>CCCCCC[C@H]1C[C@@H]1C(=O)SCC</smiles>

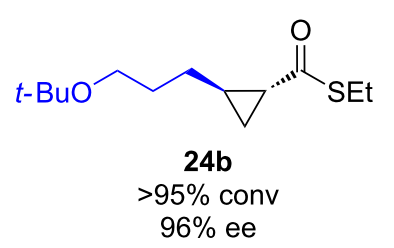<smiles>CCSC(=O)[C@H]1C[C@@H]1CCc1ccccc1</smiles>

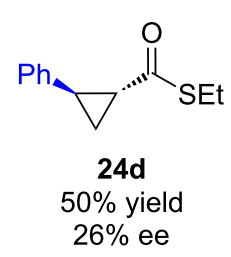

Scheme 10: Tandem Cu ECA/intramolecular enolate trapping involving 4-chloro- $\alpha, \beta$-unsaturated thioester 22.<smiles>CC(=O)/C=C/B1Nc2cccc3cccc(c23)N1</smiles>

25

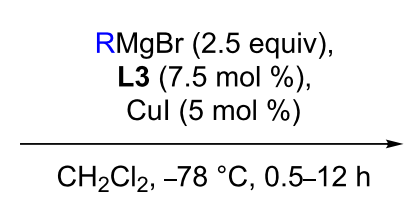

$\mathrm{CH}_{2} \mathrm{Cl}_{2},-78^{\circ} \mathrm{C}, 0.5-12 \mathrm{~h}$<smiles>[R]C(BNc1cccc2ccccc12)CC(C)=O</smiles>

26

8 examples

$50-82 \%$ yield

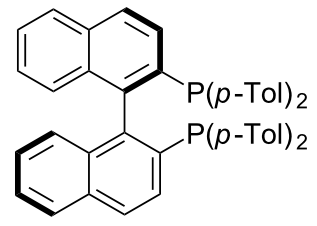

(R)-ToIBINAP

L3<smiles>CC(=O)CC(B1Nc2cccc3cccc(c23)N1)c1ccc(F)cc1</smiles>

$12 \mathrm{~h}$

26a $80 \%$ yield $95 \%$ ee<smiles>CC(=O)C[C@H](C)B1Nc2cccc3cccc(c23)N1</smiles>

$0.5 \mathrm{~h}$

26b $82 \%$ yield $98 \%$ ee<smiles>C=C(C)C1Nc2cccc3cccc(c23)N1</smiles>

$0.5 \mathrm{~h}$

26c $54 \%$ yield $0 \%$ ee

Scheme 11: Cu ECA of Grignard reagents to 3-boronyl $\alpha, \beta$-unsaturated thioesters.

(50-82\%) and ee values (82-98\%). Unfortunately, ortho-substituted aromatic or hindered alkenyl reagents led to the corresponding products without showing any enantioselectivity.

Very recently, Fletcher and Gao reported the first copper-catalyzed ECA of alkylzirconium reagents to $\alpha, \beta$-unsaturated thioesters [33]. Starting from diversely functionalized alkenes, the resulting hydrozirconated adducts were reacted with various $\beta$-substituted Michael acceptors in the presence of $\mathrm{CuCl}$ and the chiral phosphoramidite L11 (Scheme 12). Remarkably, the corresponding 1,4-products were isolated in moderate to good yields (around 70\%) and up to $99 \%$ ee. The high versatility of the protocol was illustrated by the synthesis of commercially relevant fragrances (phenoxanol and hydroxycitronellal). Additionally, an efficient iterative route was also described, allowing to produce the highly functionalized deoxypropionate fragment 30 in good overall yields and excellent stereocontrol for all stereogenic centers (up to $98: 2 \mathrm{dr}$ ). 


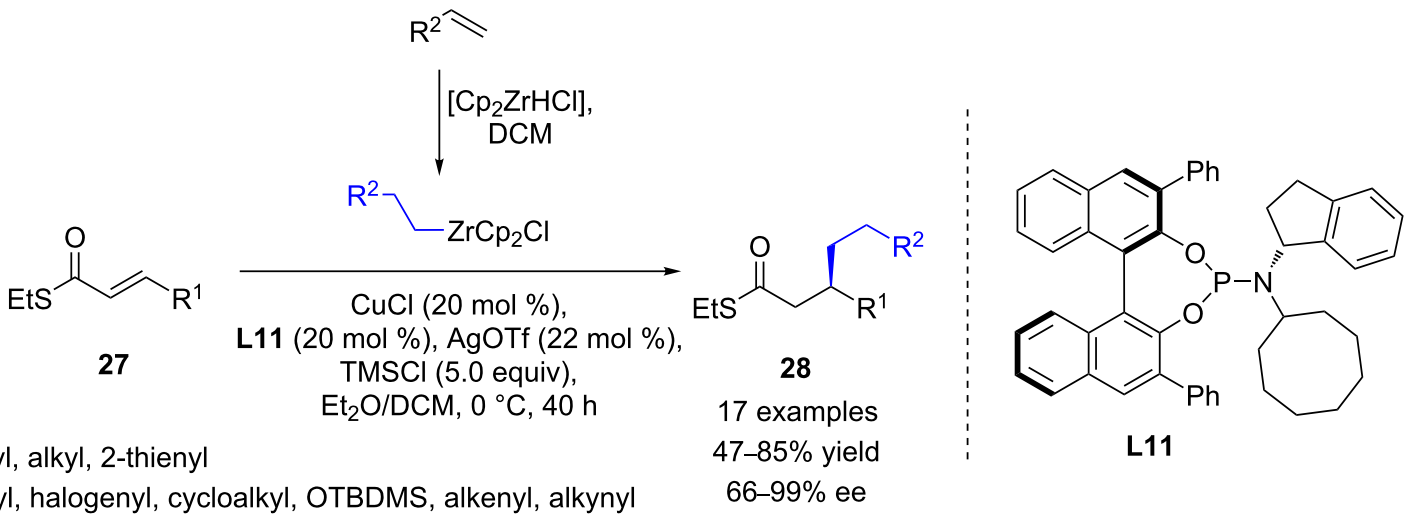

$\mathrm{R}^{2}=$ aryl, halogenyl, cycloalkyl, OTBDMS, alkenyl, alkynyl<smiles>C=CCCCCC(CCc1ccccc1)CC(=O)SCC</smiles>

28a $64 \%$ yield $92 \%$ ee<smiles>CCCC(=O)CC(C)CCc1ccccc1Br</smiles>

28b $70 \%$ yield $99 \%$ ee<smiles>CCC(=O)CC(C)CCc1ccccc1</smiles>

$28 \mathrm{c}$

$75 \%$ yield $97 \%$ ee

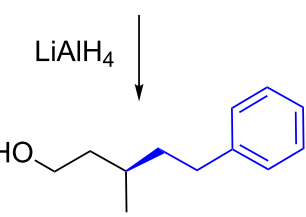<smiles>CCSC(=O)CC(C)CCCC(C)(C)OCc1ccccc1</smiles>

(R)-hydroxycitronellal<smiles>CCSC(=O)CC(C)CCCCOCc1ccccc1</smiles>

$28 \mathrm{e}$

$75 \%$ yield $98 \%$ ee
(R)-phenoxanol<smiles>CCSC(=O)CC(CCc1ccccc1Br)CC(C)CCCCCl</smiles>

$98: 2 \mathrm{dr}$

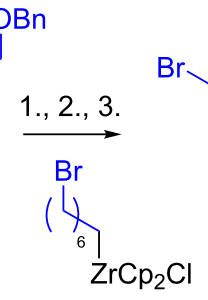
$\mathrm{ZrCp} 2 \mathrm{Cl}$<smiles>CCSC(=O)CC(CCCCCCCI)CC(CCc1ccccc1Br)CC(C)CCCCOCc1ccccc1</smiles>

30

3 steps, $60 \%$ yield $98: 2 \mathrm{dr}$

Scheme 12: Cu ECA of alkylzirconium reagents to $\alpha, \beta$-unsaturated thioesters.

\section{$\alpha, \beta$-Unsaturated acylimidazoles}

The pioneering and successful use of $\alpha, \beta$-unsaturated acylimidazoles as Michael acceptors in enantioselective catalysis was reported by Evans and co-workers in 2005 [34]. The selected asymmetric transformation was the Friedel-Crafts 1,4-addition involving indole derivatives as nucleophiles, catalyzed by a scandium(III) triflate complex with chiral bis(oxazolinyl)pyridine ligands. As highlighted by Evans, the acylimidazole moiety constituted a privileged surrogate of esters, amides, ketones, and aldehydes. Indeed, this peculiar function, which was readily accessible from the corresponding aldehydes or Weinreb amides, could be efficiently converted into a wide range of carbonyl derivatives, as depicted in Scheme 13.

The successful use of $\alpha, \beta$-unsaturated acylimidazole in $\mathrm{Cu}$ ECAs using organometallic reagents has been introduced very recently. Pioneering works in this field were published in 2011 by Roelfes, Liskamp, and co-workers, with the 1,4-addition of dimethyl malonate to cinnamyl 2-acyl-1-methylimidazole (31). Unfortunately, in the presence of $\mathrm{Cu}\left(\mathrm{NO}_{3}\right)_{2}$ and the triazacyclo- 


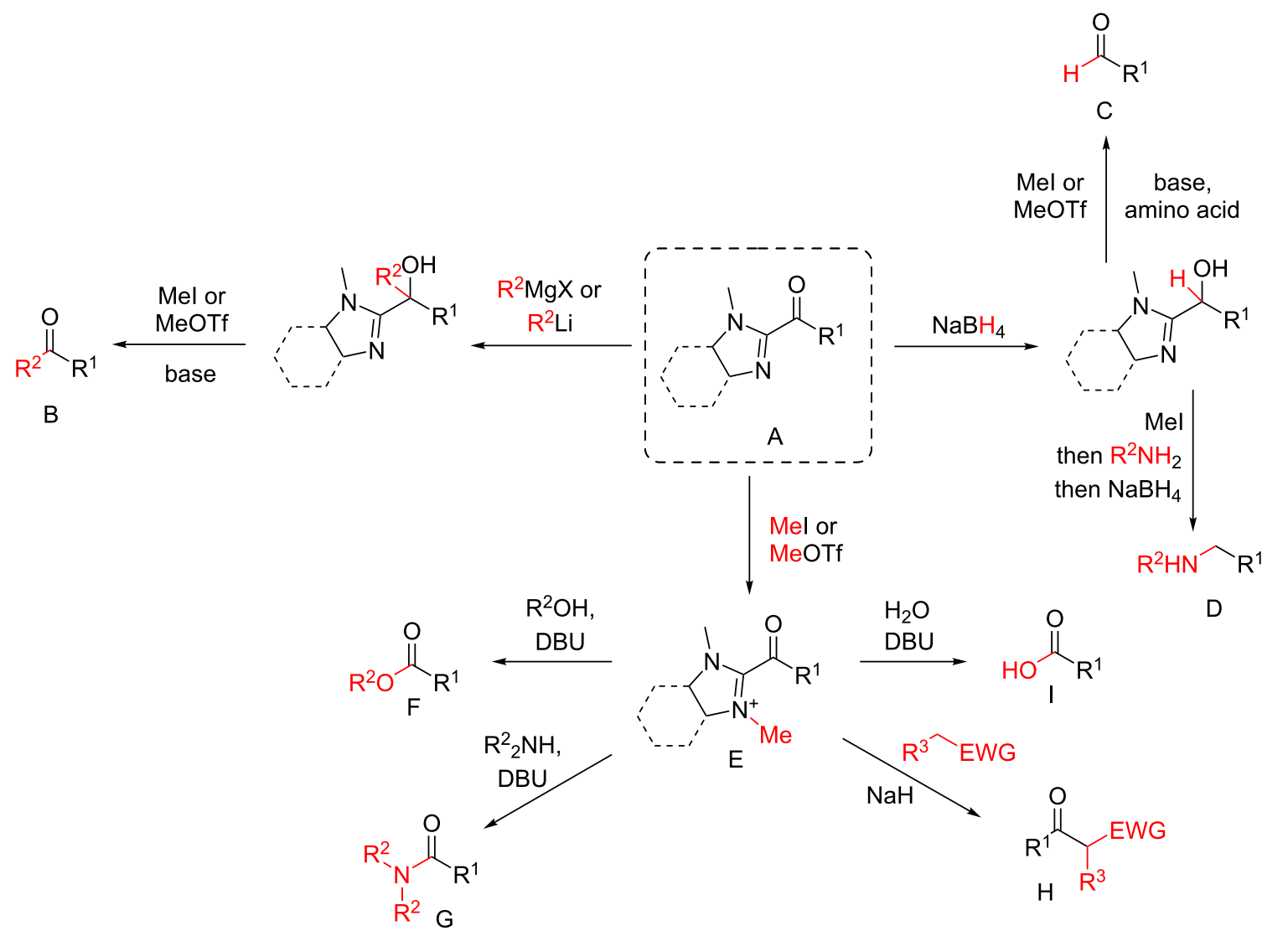

Scheme 13: Conversion of acylimidazoles into aldehydes, ketones, acids, esters, amides, and amines.

phane-based ligand L12, the product was obtained in a good yield of $90 \%$, but a poor enantioselectivity $(24 \%$ ee) was observed (Scheme 14) [35].

In 2012, Sawamura and co-workers described the first highly enantioselective copper-catalyzed conjugate addition of alkyl boranes to $\alpha, \beta$-unsaturated 2-acyl-1-methylbenzimidazoles $\mathbf{3 3}$ [36]. Based on a previous study dealing with the $\mathrm{CuCl} / \mathrm{IMes}$ - catalyzed addition of various alkylated 9BBN derivatives [37], the authors screened a set of various chiral NHC precursors. The imidazolium compound $\mathbf{L 1 3}$ appeared to be the most efficient one, affording the desired 1,4 products in high yields (57 to $93 \%$ ) and excellent ee values (up to $93 \%$, Scheme 15). Advantageously, this methodology was highly tolerant towards a wide range of functional groups, whether on alkylboranes or on substrates.<smiles>Cn1ccnc1C(=O)/C=C/c1ccccc1</smiles><smiles>COC(=O)CC(=O)OC</smiles>

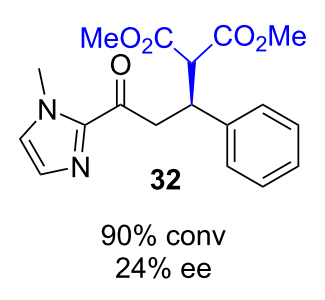

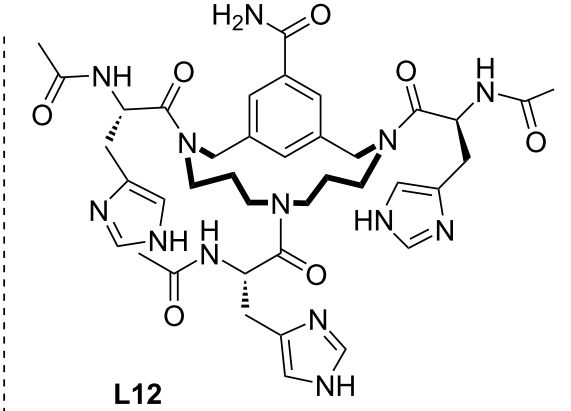

Scheme 14: Cu ECA of dimethyl malonate to $\alpha, \beta$-unsaturated acylimidazole 31 with triazacyclophane-based ligand L12. 

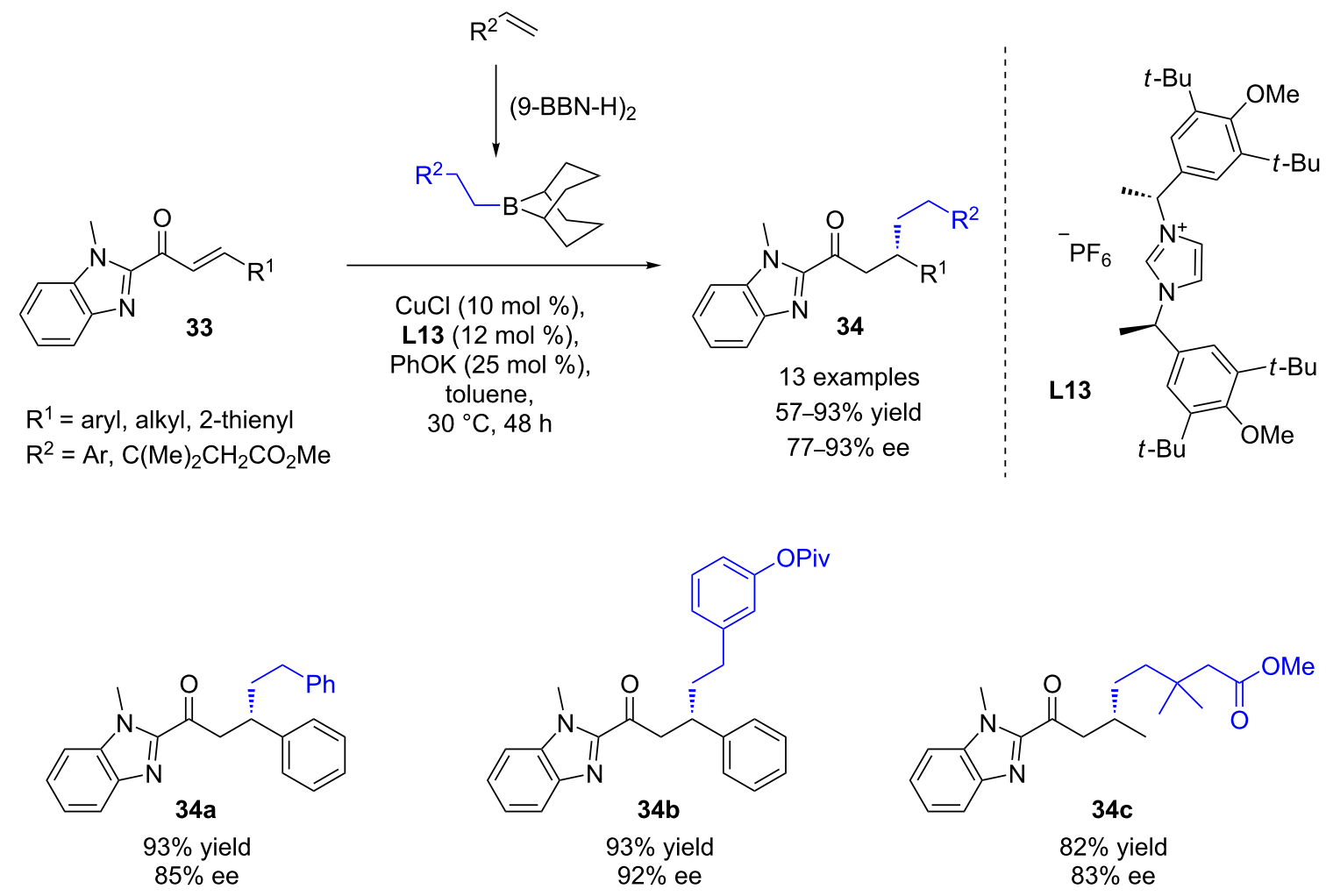

Scheme 15: Cu/L13-catalyzed ECA of alkylboranes to $\alpha, \beta$-unsaturated acylimidazoles.

In 2015, Mauduit, Campagne, and co-workers set up a highly enantioselective 1,4-addition of dimethylzinc to a wide scope of $\alpha, \beta$-unsaturated acylimidazoles 35 [38]. Among the various ligands screened in combination with copper(II) triflate, the hydroxyalkyl-chelating NHC precursor $\mathbf{L 1 4}$ proved to be the most efficient one, giving the 1,4 product with moderate to good yields (34-86\%) and excellent enantioinduction (86 to $95 \%$ ee, Scheme 16). The methodology was successfully applied to various extended Michael acceptor systems (dienic or trienic acylimidazoles), leading preferably to the corresponding 1,4 products in moderate to good yields $(28-85 \%)$ with remarkable regio- ( $>95 \%)$ and enantioselectivities (91-95\% ee) [39]. Interestingly, DFT calculations supported the crucial role of the imidazole moiety towards the 1,4 -addition (vs 1,6 or 1,8 ) [39].

Thanks to the efficient post-transformation of the acylimidazole function, the synthetic potential of this methodology was illustrated in the synthesis of relevant molecules, such as a ionone derivative, $(+)$-ar-turmerone, and (+)-Florhydral ${ }^{\circledR}$, which were formed in good yields, without alteration of their optical purity $[38,39]$.

Moreover, an iterative $\mathrm{Cu}$ ECA process allowing the selective introduction of a second methyl stereogenic center was then explored to develop a straightforward access to 1,3-deoxypropionate units, a scaffold ubiquitous in numerous natural products (Scheme 17) [40]. Starting from enantioenriched $\beta$-methylated aldehyde 37, the regeneration of the $\alpha, \beta$-unsaturated 2-acyl-1methylimidazole moiety was performed in high yield and $E / Z$ selectivity via a two-step protocol. The resulting Michael acceptor was then engaged in an ECA to afford the expected 1,3-dimethyl product in 69\% yield and a good diastereomeric excess of $94 \%$ (Scheme 17). Following this iterative methodology, the synthesis of 3,5,7-all-syn- and anti,anti-stereotriads 40a/b were successfully achieved in high diastereomeric ratios (up to >95:5) and good overall yields from $(R)$ - or $(S)$ citronellal.

More recently, Mauduit, Campagne, and co-workers reported an efficient $\mathrm{Cu} /$ Taniaphos-catalyzed $\beta$-borylation of an $\alpha, \beta$ unsaturated acylimidazole, leading to various enantioenriched $\beta$-hydroxy products after oxidation (up to $>98 \%$ ee) [41]. Interestingly, following the aforementioned iterative ECA strategy, the postfunctionalized chiral acylimidazole $\mathbf{4 1}$ derived from $(S)$ citronellal was efficiently converted to highly desirable anti,syn- and anti,anti-3,5,7-(Me,OR,Me)-substituted products 42a/b, which were isolated in good yields and excellent diastereomeric ratios (up to $>95: 5$, Scheme 18). 


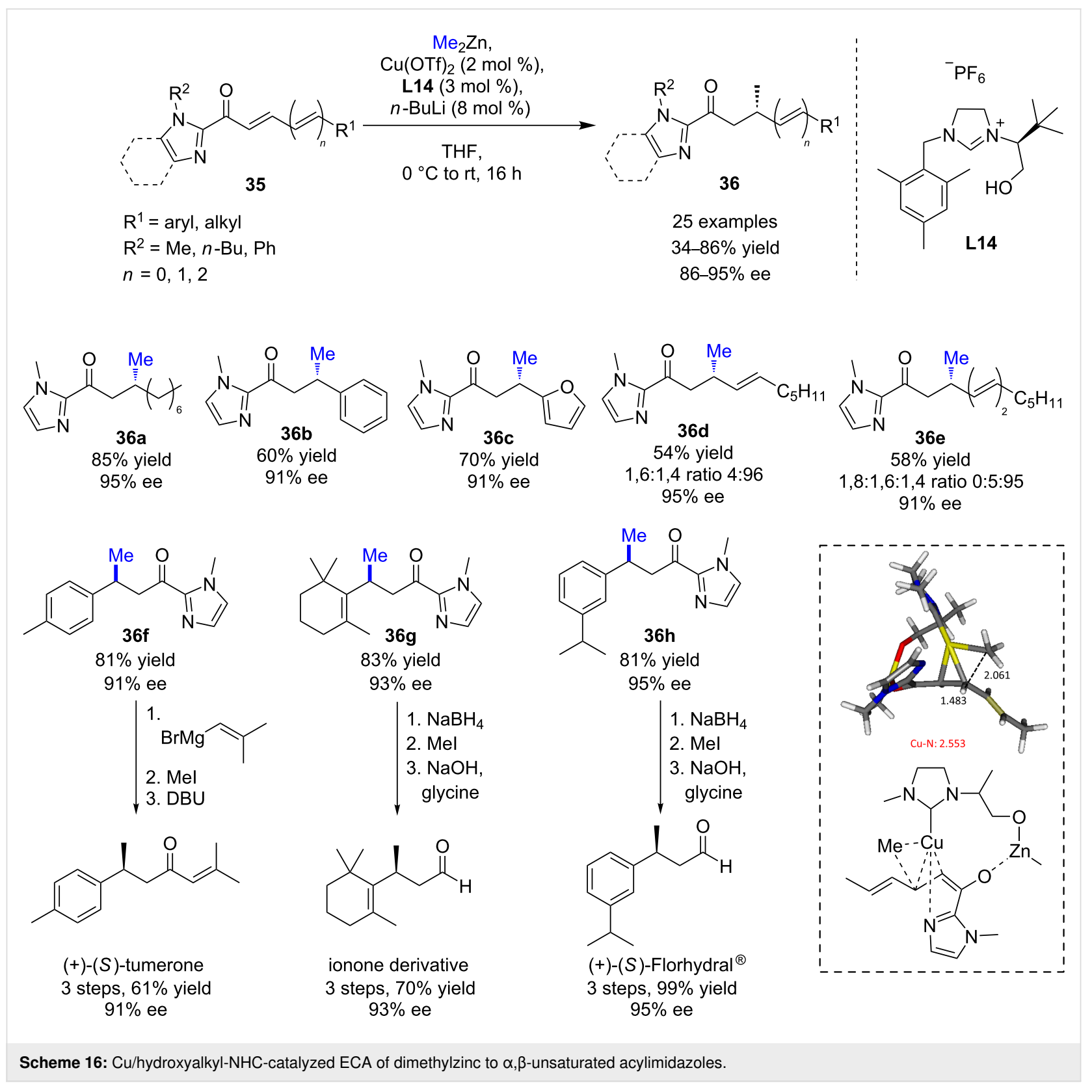

\section{$\alpha, \beta$-Unsaturated $N$-acyloxazolidinone,}

\section{$\mathrm{N}$-acylpyrrolidinone, and amide derivatives}

Similar to acylimidazole Michael acceptors, the first use of $\alpha, \beta$ unsaturated $N$-acyloxazolidinones was also described in asymmetric Friedel-Crafts 1,4-additions catalyzed by chiral copper/ bisoxazolidine Lewis acids [42-46]. Thanks to the easy posttransformation of the oxazolidine moiety, the resulting enantioenriched products (up to $99 \%$ ee) were successfully converted to relevant molecules, such as trans-whisky lactone [43].

In 2003, Hoveyda and Hird reported the first 1,4-addition of alkylmetal nucleophiles to $\alpha, \beta$-unsaturated $N$-acyloxazolidinones (Scheme 19) [47]. The chiral triamidophosphane ligand L15a as a copper(I) triflate complex efficiently promoted the catalytic conjugate addition of dialkylzinc species to various $\mathrm{N}$-acyloxazolidinone Michael acceptors, in most of the cases with high isolated yields (61 to 95\%) and excellent enantioselectivities (up to $>98 \%$ ). Furthermore, the resulting enantioenriched $\beta$-alkylated $N$-acyloxazolidinones could be converted to various derivatives (aldehydes, ketones, Weinreb amides, or carboxylic acids) in good yields and without alteration of the ee values. In 2006, aminohydroxyphosphine L15b was used as a new designer ligand by Nakamura and co-workers for the addition of diethylzinc to crotonyl $\mathrm{N}$-acyloxazolidinone [48]. The 1,4-product was also formed in high enantioselectivity (>98\% ee) and high yield (91\%). 

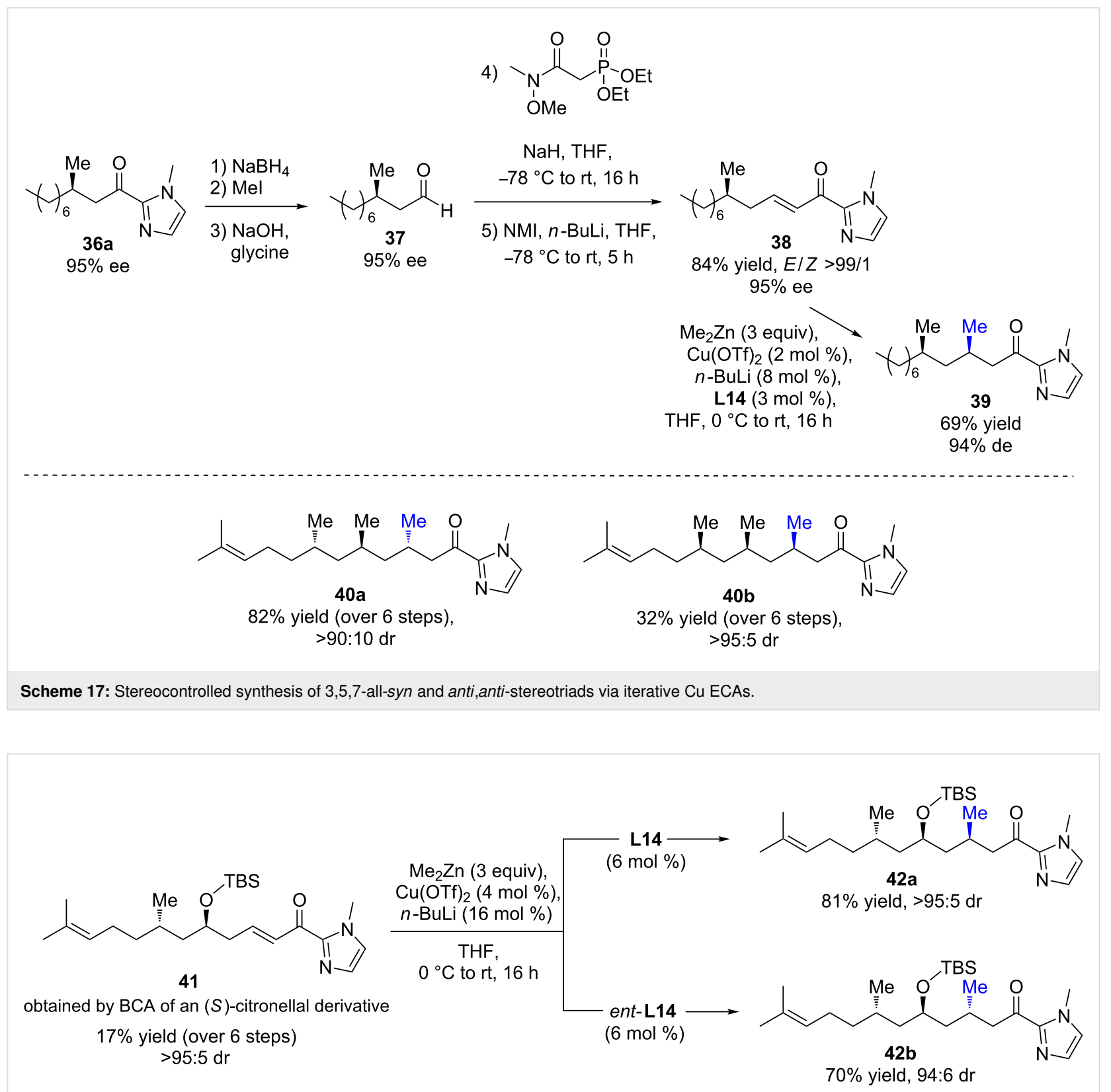

Scheme 18: Stereocontrolled synthesis of anti,syn- and anti,anti-3,5,7-(Me,OR,Me) units via iterative Cu ECA/BCA.

The same year, Pineschi et al. evaluated various $\alpha, \beta$-unsaturated acyl derivatives for the copper/ $(R, S, S)$-phosphoramidite L16-catalyzed addition of diethylzinc (Scheme 20) [49]. Although the Michael acceptor bearing the $N$-acyloxazolidinone moiety that was successfully used by Hoveyda $(95 \%$ ee) gave a lower enantioselectivity (64\%), a more satisfactory enantiocontrol was obtained with the substrate having a 2-pyrrolidinone fragment $(87 \%$ ee). The scope was then extended to various $\alpha, \beta$-unsaturated $N$-acyl-2-pyrrolidinones and dialkylzinc reagents, leading to the corresponding 1,4-products in low to good yields (7-88\%), with good to excellent enantioinduction
( 60 to $>99 \%$ ee). Trimethylaluminium reagents were also investigated, but unfortunately, only low ee values were observed (20-36\% ee), whereas no reactivity was observed with $\alpha, \beta$ unsaturated amides.

Although Pineschi's conditions were ineffective for amides [49], Harutyunyan and co-workers achieved an important breakthrough by reporting the first enantioselective alkylation of $\alpha, \beta$-unsaturated amides [50]. Indeed, due to their poor reactivity compared to other Michael acceptors, catalytic asymmetric conjugate additions of organometallic reagents to $N, N$ - 


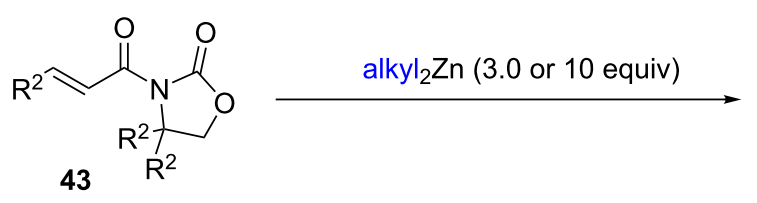<smiles>[R]C([AlH2])CC(=O)N1C(=O)OC[R1]1([R])[H]</smiles>

L15a (2.4-6 mol \%), (CuOTf) $)_{2} \cdot \mathrm{C}_{6} \mathrm{H}_{6}(0.5-2.5 \mathrm{~mol} \%)$, toluene, $-15^{\circ} \mathrm{C}$ to $0{ }^{\circ} \mathrm{C}$ 8 examples $61-95 \%$ yield 76 to $>98 \%$ ee<smiles>CCCCNC(=O)[C@H](NC(=O)C(NC(=O)c1ccccc1P)C(C)C)C(C)OCCCC</smiles>

L15a<smiles>CCC(CCCO[R15](C)(F)F)CC(=O)N1CCOC1=O</smiles><smiles>CCCCNC(=O)C(O)[C@@H](O)c1ccccc1P</smiles>

L15b<smiles>CCC(C)CC(=O)N1CCOC1=O</smiles>

$44 a$

$95 \%$ yield

95\% ee

44c

$95 \%$ yield

$>98 \%$ ee<smiles>CCC(C)CC(=O)N1CCOC1=O</smiles><smiles>CC(C)CCC[C@H](C)CC(=O)N1CCOC1=O</smiles>

44b $61 \%$ yield $93 \%$ ee<smiles>CCC(CC(=O)N1C(=O)OCC1(C)C)c1ccccc1</smiles>

44d

$91 \%$ yield $86 \%$ ee
L15b (6 mol \%), $\mathrm{Cu}(\mathrm{OTf})_{2}(5 \mathrm{~mol} \%)$, $\mathrm{CH}_{2} \mathrm{Cl}_{2}, 0^{\circ} \mathrm{C}$<smiles>CCC(C)CC(=O)O</smiles>

45<smiles>CNC(=O)C[C@H](C)CCCC(C)C</smiles>

46

$74 \%$ yield $93 \%$ ee from $44 b$ 44a

$91 \%$ yield $98.7 \%$ ee<smiles>CC(C)CCC[C@H](C)CC(=O)C(C)(C)C</smiles>

47

$81 \%$ yield $93 \%$ ee from $44 b$<smiles>[R]C=CC(=O)N1CCCC1=O</smiles>

48

$\mathrm{R}=$ alkyl, aryl, alkenes<smiles>CCC(CC(=O)N1CCCC1=O)C(C)C</smiles>

$49 a$

$75 \%$ yield $95 \%$ ee
L16 (3.0 mol \%), $\mathrm{Cu}(\mathrm{OTf})_{2}(1.5 \mathrm{~mol} \%)$, alkyl 2 Zn (3.0 equiv)

toluene, $-78^{\circ} \mathrm{C}$ to $0{ }^{\circ} \mathrm{C}$

23 examples

$7-88 \%$ yield 60 to $>99 \%$ ee

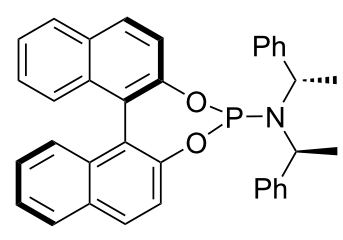

$(R, S, S)-\mathbf{L} 16$<smiles>CC(C)[C@H](CC(=O)N1CCCC1=O)c1ccccc1</smiles>

$49 b$

$75 \%$ yield $81 \%$ ee<smiles>CCC(CC(=O)N1CCCC1=O)c1ccc(C)cc1</smiles>

$49 c$

$84 \%$ yield $>99 \%$ ee

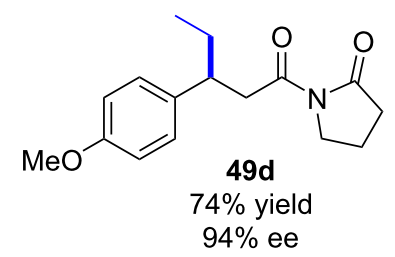

Scheme 20: Cu/phosphoramidite L16-catalyzed ECA of dialkylzincs to $\alpha, \beta$-unsaturated $N$-acyl-2-pyrrolidinones. 
dialkylenamides remained a real challenge. However, thanks to the synergistic action of the boron-based Lewis acid $\mathrm{BF}_{3} \cdot \mathrm{Et}_{2} \mathrm{O}$, $\mathrm{CuBr} \cdot \mathrm{SMe}_{2}$, and the chiral (R,S)-Josiphos ligand (L9), an efficient (yields up to $86 \%$ ) and highly regio- and enantioselective (ee values up to $99 \%$ ) protocol was developed for 1,4-additions of various Grignard reagents to a wide scope of substrates (Scheme 21). Notably, the introduction of methyl and functionalized alkyl groups was performed with remarkable stereoselectivity (97-99\%). Furthermore, this catalytic system was easily upscalable (up to $10 \mathrm{~g}$ ), and the chiral catalyst could be recycled without any loss of efficiency. Unfortunately, although a wide range of Grignard reagents led to excellent results, $\mathrm{PhMgBr}$ provided low conversion and the racemic 1,4product. Additionally, amide substrates featuring a bis(paramethoxybenzyl) moiety could be converted into relevant $\beta$-alkyl-substituted chiral amines, ubiquitous in numerous pharmaceutical ingredients, such as $\mathbf{5 2}$, a direct precursor of a drug candidate. Moreover, tandem ECA/enolate trapping was also studied, providing the trans-cyclopentane product $\mathbf{5 6}$ as a single diastereoisomer (92\% ee).

In 2018, the same authors reported the 1,6- and 1,4-additions of various Grignard reagents to a wide scope of conjugated dienyl amides (Scheme 22) [51]. Interestingly, the authors observed<smiles>[R]NC(=O)C=[18O]</smiles>

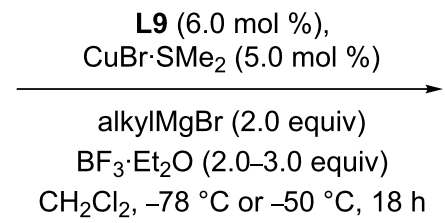

$\mathrm{R}^{2}, \mathrm{R}^{3}=$ alkyl, allyl, aryl, heterocycle<smiles>[R]C([13CH3])CC(=O)N([R])[R]</smiles>

34 examples $41-93 \%$ yield $77-99 \%$ ee

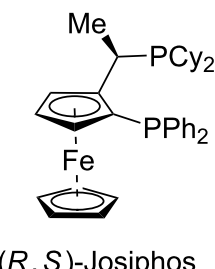

$(R, S)$-Josiphos

L9 alkyl = Me, Et, $n$-Hex, cyclopentyl, isobutyl, isopentyl, $\mathrm{CH}_{2} \mathrm{Bn}$, alkenyl $\mathrm{PMB}=$ para-methoxybenzyl<smiles>CCC(C)CC(=O)N(C)C</smiles>

$51 \mathrm{a}$

$79 \%$ yield $94 \%$ ee<smiles>C=CCCCC(P)CC(=O)N(C)C</smiles>

$51 \mathrm{~b}$

$80 \%$ yield $97 \%$ ee<smiles>CCC(C)CC(=O)N1CCOCC1</smiles>

$51 \mathrm{c}$

$75 \%$ yield $96 \%$ ee<smiles>CCCC(CCCCCl)CC(=O)N(C)C</smiles>

51d

$41 \%$ yield $98 \%$ ee<smiles>CCC(CC)CC(=O)NP(C)(C)=O</smiles>

'PMB

$$
51 \text { e }
$$

$72 \%$ yield

$97 \%$ ee

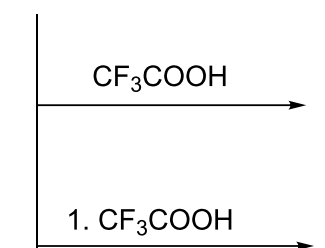

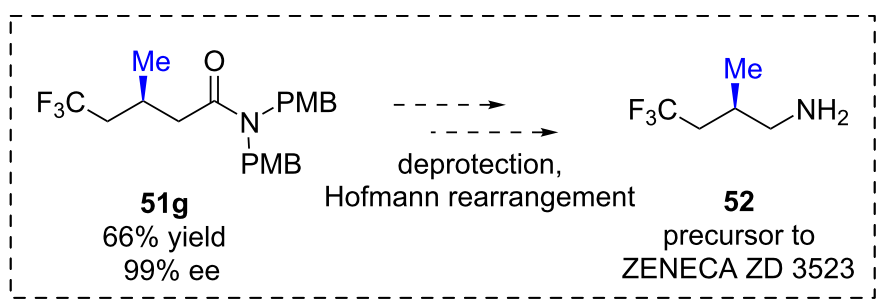

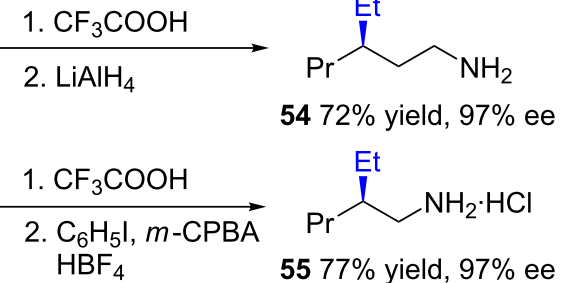<smiles>CCOCCOCCOCCO</smiles><smiles>CCC1CCCC1C(=O)N(C)C</smiles>

$5666 \%$ yield, $92 \%$ ee 


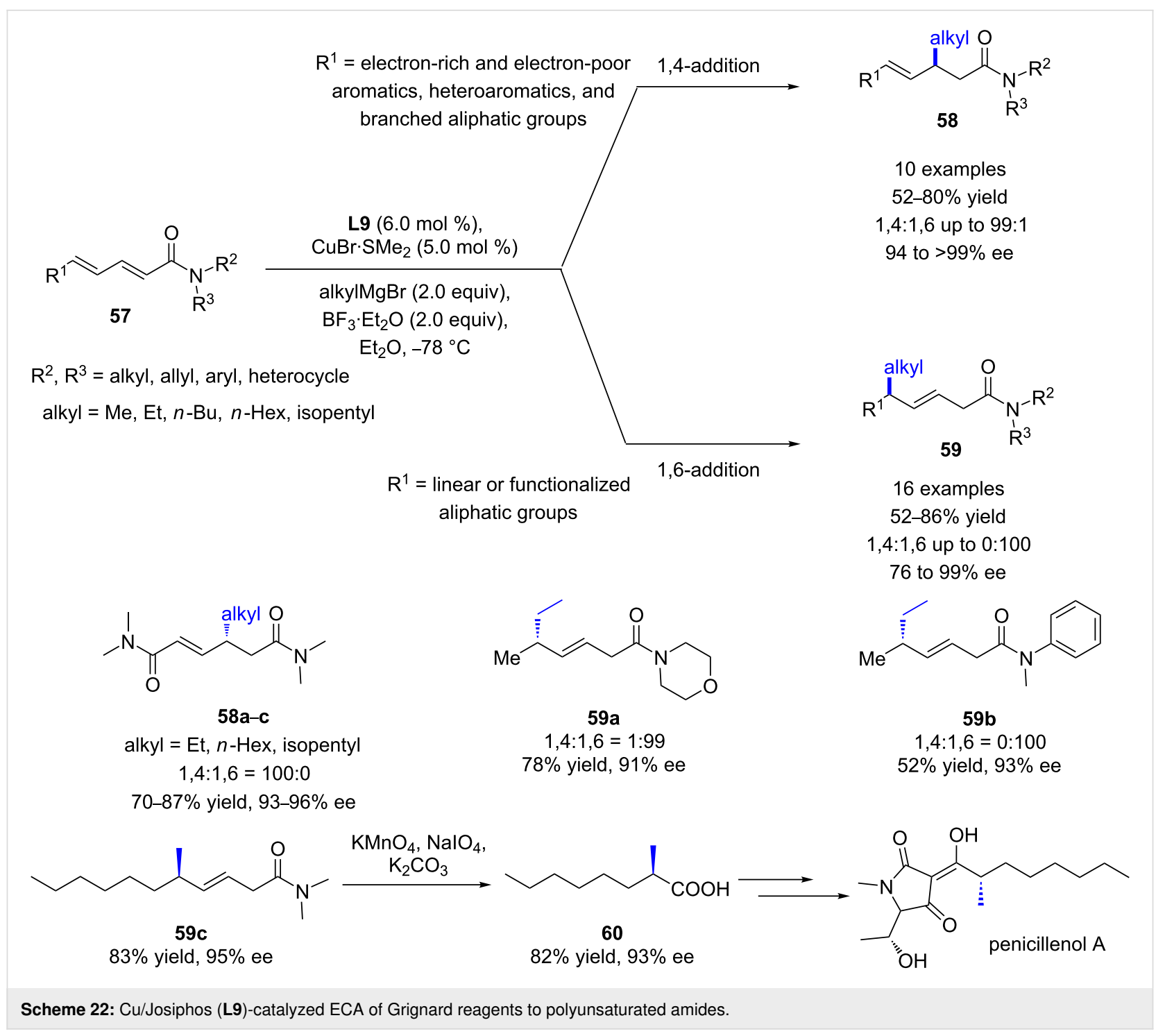

that the regioselectivity was directed by the substituent in the $\delta$-position of the substrate: dienic amides featuring linear or functionalized aliphatic substituents in the $\delta$-position led predominantly to 1,6 -products, whereas those featuring electronrich and electron-poor aromatic, heteroaromatic, and branched aliphatic substituents in the $\delta$-position afforded preferably the 1,4-products. Importantly, when the morpholine moiety was used as $\mathrm{N}$-substituent, the addition of diethylzinc to the enamide afforded the 1,6-addition product with $78 \%$ isolated yield and $91 \%$ ee. It is worth to underline that the morpholine group could easily allow further postfunctionalizations. Furthermore, thanks to the highly 1,6 -enantioselective additions of methylmagnesium bromide ( $95 \%$ ee), this methodology was applied to the synthesis of the natural product penicillenol A by oxidative cleavage of the resulting 1,6 product 59c, affording the key synthon 60 with a slight erosion of the optical purity (Scheme 22).

\section{$\alpha, \beta$-Unsaturated $N$-acylpyrroles}

$\alpha, \beta$-Unsaturated $N$-acylpyrroles were also investigated as Michael acceptors in enantioselective conjugate additions using organometallic reagents. In 2013, Endo and Shibata described a catalytic system based on multinuclear copper/aluminium complexes and phenolphosphine-based ligands L17a/b and L18, allowing the selective 1,4 -addition of trimethylaluminium to three $\alpha, \beta$-unsaturated $N$-acylpyrroles with moderate to good yields (54 to 87\%) and excellent enantioselectivities (94 to $97 \%$ ee, Scheme 23) [52]. This methodology was successfully applied to the synthesis of various natural molecules, such as $(S)$-Florhydral ${ }^{\circledR}$ and $(S)$-(+)-ar-turmerone or key intermediates in the synthesis of 8-deoxyanisatin and frondosin.

\section{Conclusion}

The enantioselective $\mathrm{Cu}$-catalyzed conjugate addition of organometallic reagents to Michael acceptors has been exten- 


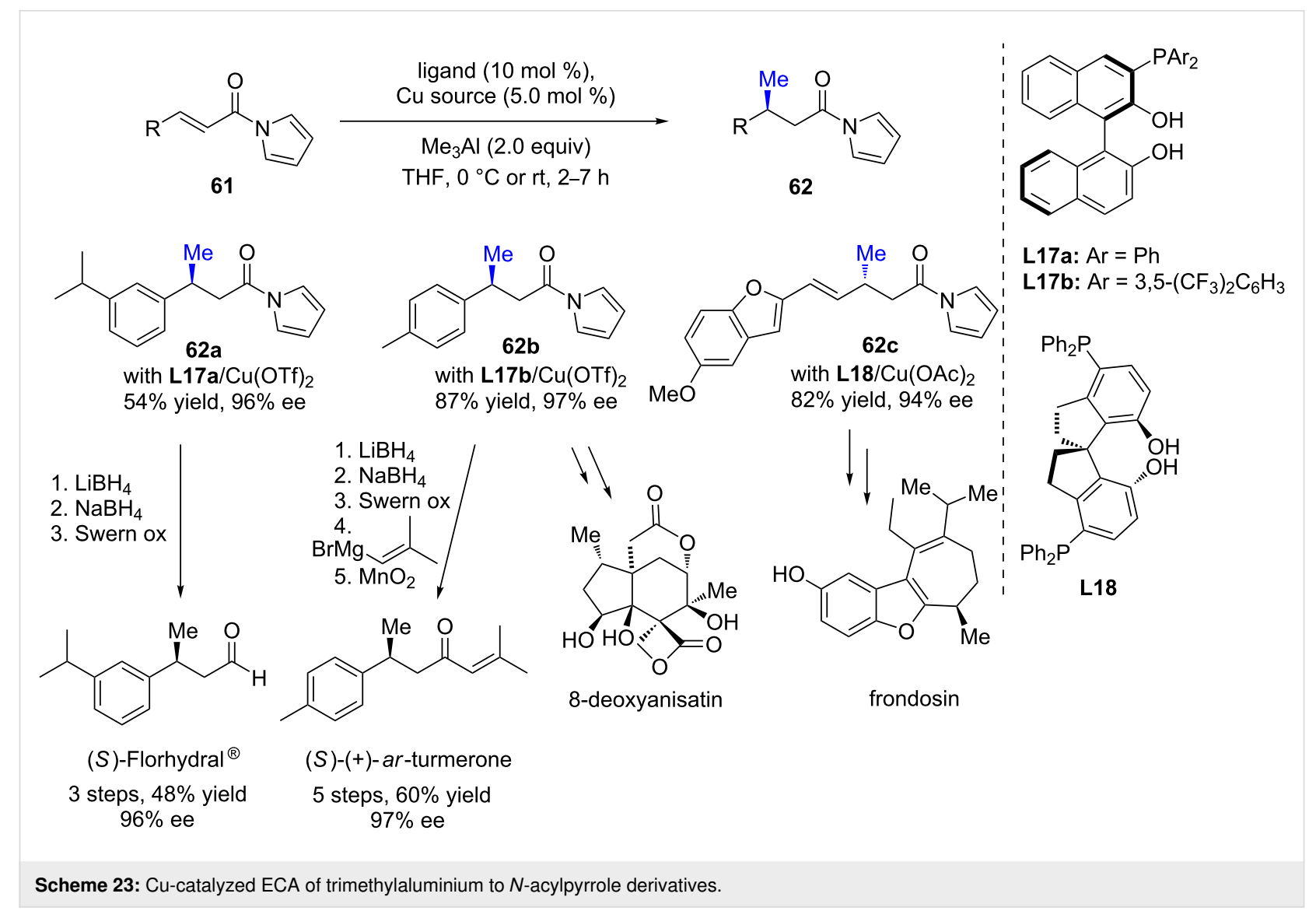

sively studied for many decades and led to remarkable results. However, for a long time, some classes of Michael acceptors ( $\alpha, \beta$-unsaturated aldehydes, thioesters, acylimidazoles, $N$-acyloxazolidinone, $N$-acylpyrrolidinone, amides, $N$-acylpyrroles) have been neglected to varying degrees, probably owing to their particular reactivity, which led to less impressive results. Nevertheless, these substrates present a high potential in total synthesis, since the chiral products can be easily transformed into various natural compounds. For example, the aldehyde function, which is directly obtained from $\alpha, \beta$-unsaturated aldehydes or is accessible through postderivatization of either acylimidazole or thioester functions, is present in many natural compounds and is also a key functional group for many synthetic strategies. Furthermore, some of the functional groups listed above can be converted into various other synthetically useful groups, such as ketones, esters, carboxylic acids, and (Weinreb) amide groups.

More recently, some works were reported, which showed that through a judicious selection of chiral ligands and a fine-tuning of the reactivities of both partners, interesting selectivities could be reached with these more challenging electron-deficient alkenes, including, in some cases, di- or trienic acceptors, which accordingly extends the scope and the synthetic applicability of the method. The potential of the methodology has been illustrated through the efficient conversion of some 1,4-products into various chiral natural products. In addition, iterative procedures leading to chiral 1,3,5-(Me,Me,Me) and 1,3,5$(\mathrm{Me}, \mathrm{OH}, \mathrm{Me})$ motifs in a stereocontrolled way were successfully applied from $\alpha, \beta$-unsaturated acylimidazoles and $\alpha, \beta$-unsaturated thioesters, and thus opening a new field for the total synthesis of natural products. We hope that the results collected in this review will encourage chemists on one hand to continue the search for improved procedures combining simple, easily accessible chiral ligands, lower catalytic loadings, high ee values and productivity, and a wide scope, and on the other hand, to include this highly promising methodology in many synthetic strategies.

\section{Acknowledgements}

We are grateful to the Ecole Nationale Supérieure de Chimie de Rennes (ENSCR) and the Centre National de la Recherche Scientifique (CNRS).

\section{Funding}

M.M., C.C. and J.M. thank the Région Bretagne (ARED 2018 "Biometa" $N^{\circ}$ 601). M.M and D.P. thank the Agence Nationale 
de la Recherche (ANR-16-CE07-0019 Hel-NHC) for their financial support.

\section{ORCID ${ }^{\circledR}$ iDs}

Delphine Pichon - https://orcid.org/0000-0002-2307-6388 Jennifer Morvan - https://orcid.org/0000-0003-1210-7975 Christophe Crévisy - https://orcid.org/0000-0001-5145-1600 Marc Mauduit - https://orcid.org/0000-0002-7080-9708

\section{References}

1. Mauduit, M.; Baslé, O.; Clavier, H.; Crévisy, C.; Denicourt-Nowicki, A. Metal-Catalyzed Asymmetric Nucleophilic Addition to Electron-Deficient Alkenes. In Comprehensive Organic Synthesis, 2nd ed.; Molander, G. A.; Knochel, P., Eds.; Elsevier: Amsterdam, Netherlands, 2014; Vol. 4, pp 189-341. doi:10.1016/b978-0-08-097742-3.00406-7

2. Alexakis, A.; Bäckvall, J. E.; Krause, N.; Pàmies, O.; Diéguez, M. Chem. Rev. 2008, 108, 2796-2823. doi:10.1021/cr0683515

3. Harutyunyan, S. R.; den Hartog, T.; Geurts, K.; Minnaard, A. J.; Feringa, B. L. Chem. Rev. 2008, 108, 2824-2852. doi:10.1021/cr068424k

4. Jerphagnon, T.; Pizzuti, M. G.; Minnaard, A. J.; Feringa, B. L. Chem. Soc. Rev. 2009, 38, 1039-1075. doi:10.1039/b816853a

5. Alexakis, A.; Frutos, J.; Mangeney, P. Tetrahedron: Asymmetry 1993, 4, 2427-2430. doi:10.1016/s0957-4166(00)82216-8

6. Martin, D.; Kehrli, S.; d'Augustin, M.; Clavier, H.; Mauduit, M.; Alexakis, A. J. Am. Chem. Soc. 2006, 128, 8416-8417. doi:10.1021/ja0629920

7. Tissot, M.; Li, H.; Alexakis, A. Copper-catalyzed asymmetric conjugate addition and allylic substitution of organometallic reagents to extended multiple bond systems. In Copper catalyzed asymmetric synthesis; Alexakis, A.; Krause, N.; Woodward, S., Eds.; Wiley-VCH: Weinheim, Germany, 2014; pp 69-84. doi:10.1002/9783527664573.ch3

8. Schmid, T. E.; Drissi-Amraoui, S.; Crévisy, C.; Baslé, O.; Mauduit, M. Beilstein J. Org. Chem. 2015, 11, 2418-2434. doi:10.3762/bjoc.11.263

9. den Hartog, T.; Huang, Y.; Fañanás-Mastral, M.; Meuwese, A.; Rudolph, A.; Pérez, M.; Minnaard, A. J.; Feringa, B. L. ACS Catal. 2015, 5, 560-574. doi:10.1021/cs501297s See for mechanistic considerations.

10. Calvo, B. C.; Buter, J.; Minnaard, A. J. Applications to the synthesis of natural products. In Copper-Catalyzed Asymmetric Synthesis; Alexakis, A.; Krause, N.; Woodward, S., Eds.; Wiley-VCH: Weinheim, Germany, 2014; pp 373-448. doi:10.1002/9783527664573.ch14

11. Jones, P.; Reddy, C. K.; Knochel, P. Tetrahedron 1998, 54 , 1471-1490. doi:10.1016/s0040-4020(97)10382-9 See for previous results in copper-free conjugate addition of organometallic reagents to $\alpha, \beta$-unsaturated aldehydes.

12. Bräse, S.; Höfener, S. Angew. Chem., Int. Ed. 2005, 44, 7879-7881. doi:10.1002/anie.200501732

See for the first enantioselective copper-free conjugate addition of organometallic reagents to $\alpha, \beta$-unsaturated aldehydes.

13. Marshall, J. A.; Herold, M.; Eidam, H. S.; Eidam, P. Org. Lett. 2006, 8, 5505-5508. doi:10.1021/ol062154a

See for the first copper-catalyzed diastereoselective conjugate addition of organometallic reagents to $\alpha, \beta$-unsaturated aldehydes.

14. Palais, L.; Babel, L.; Quintard, A.; Belot, S.; Alexakis, A. Org. Lett. 2010, 12, 1988-1991. doi:10.1021/ol100441r

15. Corey, E. J.; Boaz, N. W. Tetrahedron Lett. 1985, 26, 6015-6018. doi:10.1016/s0040-4039(00)95113-x
16. Corey, E. J.; Boaz, N. W. Tetrahedron Lett. 1985, 26, 6019-6022. doi:10.1016/s0040-4039(00)95114-1

17. Alexakis, A.; Berlan, J.; Besace, Y. Tetrahedron Lett. 1986, 27 1047-1050. doi:10.1016/s0040-4039(86)80044-2

18. Nakamura, E.; Matsuzawa, S.; Horiguchi, Y.; Kuwajima, I. Tetrahedron Lett. 1986, 27, 4029-4032. doi:10.1016/s0040-4039(00)84902-3

19. Chuit, C.; Foulon, J. P.; Normant, J. F. Tetrahedron 1980, 36, 2305-2310. doi:10.1016/0040-4020(80)80126-8

20. Gremaud, L.; Palais, L.; Alexakis, A. Chimia 2012, 66, 196-200. doi:10.2533/chimia.2012.196

21. Quintard, A.; Alexakis, A. Adv. Synth. Catal. 2010, 352, 1856-1860. doi:10.1002/adsc.201000309

22. Afewerki, S.; Breistein, P.; Pirttilä, K.; Deiana, L.; Dziedzic, P.; Ibrahem, I.; Córdova, A. Chem. - Eur. J. 2011, 17, 8784-8788. doi:10.1002/chem.201100756

23. Fañanas-Mastral, M.; Feringa, B. L. J. Am. Chem. Soc. 2010, 132, 13152-13153. doi:10.1021/ja105585y

See for a relevant alternative copper catalytic process based on the in situ enantioselective allylic alkylation of $\alpha, \beta$-unstaurated aldehydes leading to $\beta$-substituted aldehydes with high ee values (up to 94\%).

24. Goncalves-Contal, S.; Gremaud, L.; Palais, L.; Babel, L.; Alexakis, A. Synthesis 2016, 48, 3301-3308. doi:10.1055/s-0035-1562487

25. Des Mazery, R.; Pullez, M.; López, F.; Harutyunyan, S. R.; Minnaard, A. J.; Feringa, B. L. J. Am. Chem. Soc. 2005, 127, 9966-9967. doi:10.1021/ja053020f

26. Maciá Ruiz, B.; Geurts, K.; Fernández-lbáñez, M. Á.; ter Horst, B.; Minnaard, A. J.; Feringa, B. L. Org. Lett. 2007, 9, 5123-5126. doi:10.1021/ol702425a

27. Bates, R. W.; Sridhar, S. J. Org. Chem. 2008, 73, 8104-8105. doi:10.1021/jo801433f

28. van Zijl, A. W.; Szymanski, W.; Lopez, F.; Minnaard, A. J.; Feringa, B. L. J. Org. Chem. 2008, 73, 6994-7002. doi:10.1021/j08010649

29. den Hartog, T.; Harutyunyan, S. R.; Font, D.; Minnaard, A. J.; Feringa, B. L. Angew. Chem., Int. Ed. 2008, 47, 398-401. doi:10.1002/anie.200703702

30. den Hartog, T.; Jan van Dijken, D.; Minnaard, A. J.; Feringa, B. L. Tetrahedron: Asymmetry 2010, 21, 1574-1584. doi:10.1016/j.tetasy.2010.04.057

31. den Hartog, T.; Rudolph, A.; Macia, B.; Minnaard, A. J.; Feringa, B. L. J. Am. Chem. Soc. 2010, 132, 14349-14351. doi:10.1021/ja105704m

32. Lee, J. C. H.; Hall, D. G. J. Am. Chem. Soc. 2010, 132, 5544-5545. doi:10.1021/ja9104057

33. Gao, Z.; Fletcher, S. P. Chem. Commun. 2017, 53, 10216-10219. doi:10.1039/c7cc05433e

34. Evans, D. A.; Fandrick, K. R.; Song, H.-J. J. Am. Chem. Soc. 2005, 127, 8942-8943. doi:10.1021/ja052433d

35. Bauke Albada, H.; Rosati, F.; Coquière, D.; Roelfes, G.; Liskamp, R. M. J. Eur. J. Org. Chem. 2011, 1714-1720. doi:10.1002/ejoc.201001522

36. Yoshida, M.; Ohmiya, H.; Sawamura, M. J. Am. Chem. Soc. 2012, 134, 11896-11899. doi:10.1021/ja304481a

37. Ohmiya, H.; Yoshida, M.; Sawamura, M. Org. Lett. 2011, 13, 482-485. doi:10.1021/ol102819k

38. Drissi-Amraoui, S.; Morin, M. S. T.; Crévisy, C.; Baslé, O.; Marcia de Figueiredo, R.; Mauduit, M.; Campagne, J.-M. Angew. Chem., Int. Ed. 2015, 54, 11830-11834. doi:10.1002/anie.201506189 
39. Drissi-Amraoui, S.; Schmid, T. E.; Lauberteaux, J.; Crévisy, C.;

Baslé, O.; de Figueiredo, R. M.; Halbert, S.; Gérard, H.; Mauduit, M.; Campagne, J.-M. Adv. Synth. Catal. 2016, 358, 2519-2540. doi:10.1002/adsc.201600458

40. ter Horst, B.; Feringa, B. L.; Minnaard, A. J. Chem. Commun. 2010, 46, 2535-2547. doi:10.1039/b926265b See for a review on iterative ECA processes.

41. Lauberteaux, J.; Crévisy, C.; Baslé, O.; de Figueiredo, R. M.; Mauduit, M.; Campagne, J.-M. Org. Lett. 2019, 21, 1872-1876. doi:10.1021/acs.orglett.9b00479

42. Kitajima, H.; Katsuki, T. Synlett 1997, 568-570. doi:10.1055/s-1997-3235

43. Nishikori, H.; Ito, K.; Katsuki, T. Tetrahedron: Asymmetry 1998, 9 , 1165-1170. doi:10.1016/s0957-4166(98)00080-9

44. Evans, D. A.; Willis, M. C.; Johnston, J. N. Org. Lett. 1999, 1, 865-868. doi:10.1021/ol9901570

45. Evans, D. A.; Rovis, T.; Johnson, J. S. Pure Appl. Chem. 1999, 71 , 1407-1415. doi:10.1351/pac199971081407

46. Evans, D. A.; Scheidt, K. A.; Johnston, J. N.; Willis, M. C. J. Am. Chem. Soc. 2001, 123, 4480-4491. doi:10.1021/ja010302g

47. Hird, A. W.; Hoveyda, A. H. Angew. Chem., Int. Ed. 2003, 42, 1276-1279. doi:10.1002/anie.200390328

48. Hajra, A.; Yoshikai, N.; Nakamura, E. Org. Lett. 2006, 8, 4153-4155. doi:10.1021/ol0618306

49. Pineschi, M.; Del Moro, F.; Di Bussolo, V.; Macchia, F. Adv. Synth. Catal. 2006, 348, 301-304. doi:10.1002/adsc.200505309

50. Rodríguez-Fernández, M.; Yan, X.; Collados, J. F.; White, P. B.; Harutyunyan, S. R. J. Am. Chem. Soc. 2017, 139, 14224-14231. doi:10.1021/jacs.7b07344

51. Guo, Y.; Kootstra, J.; Harutyunyan, S. R. Angew. Chem., Int. Ed. 2018, 57, 13547-13550. doi:10.1002/anie.201808392

52. Endo, K.; Hamada, D.; Yakeishi, S.; Shibata, T. Angew. Chem., Int. Ed. 2013, 52, 606-610. doi:10.1002/anie.201206297

\section{License and Terms}

This is an Open Access article under the terms of the Creative Commons Attribution License (https://creativecommons.org/licenses/by/4.0). Please note that the reuse, redistribution and reproduction in particular requires that the authors and source are credited.

The license is subject to the Beilstein Journal of Organic Chemistry terms and conditions:

(https://www.beilstein-journals.org/bjoc)

The definitive version of this article is the electronic one which can be found at: $\underline{\text { doi:10.3762/bjoc. } 16.24}$ 